\title{
EGFR associated expression profiles vary with breast tumor subtype
}

Katherine A Hoadley¹,2,3, Victor J Weigman'2,3,4, Cheng Fan²,3, Lynda R Sawyer ${ }^{5}$, Xiaping He ${ }^{2,3}$, Melissa A Troester ${ }^{6}$, Carolyn I Sartor ${ }^{3,7}$, Thais Rieger-House ${ }^{8}$, Philip S Bernard ${ }^{8}$, Lisa A Carey ${ }^{5}$ and Charles M Perou*1,2,3,9

\begin{abstract}
Address: ${ }^{1}$ Curriculum in Genetics and Molecular Biology, University of North Carolina at Chapel Hill, Chapel Hill, NC, USA, ${ }^{2}$ Department of Genetics, University of North Carolina at Chapel Hill, Chapel Hill, NC, USA, ${ }^{3}$ Lineberger Comprehensive Cancer Center, University of North Carolina at Chapel Hill, Chapel Hill, NC, USA, ${ }^{4}$ Department of Biology, Program of in Bioinformatics and Computational Biology, University of North Carolina at Chapel Hill, Chapel Hill, NC, USA, 5 Division of Hematology/Oncology, Department of Medicine, University of North Carolina at Chapel Hill, Chapel Hill, NC, USA, ${ }^{6}$ Department of Public Health - Biostatistics and Epidemiology Concentration, University of Massachusetts Amherst, Amherst, MA, USA, ${ }^{7}$ Department of Radiation Oncology, University of North Carolina at Chapel Hill, Chapel Hill, NC, USA, ${ }^{8} \mathrm{Huntsman}$ Cancer Institute and Department of Pathology, University of Utah School of Medicine, Salt Lake City, UT, USA and ${ }^{9}$ Department of Pathology \& Laboratory Medicine, University of North Carolina at Chapel Hill, Chapel Hill, NC, USA

Email: Katherine A Hoadley - katherine.hoadley@gmail.com; Victor J Weigman - victor@med.unc.edu; Cheng Fan - cfan2000@gmail.com; Lynda R Sawyer - Irsawyer@med.unc.edu; Xiaping He - xiaping@med.unc.edu; Melissa A Troester - troester@schoolph.umass.edu; Carolyn I Sartor - carolyn_sartor@med.unc.edu; Thais Rieger-House - thais.riegerhouse@hci.utah.edu;

Philip S Bernard - phil.bernard@hci.utah.edu; Lisa A Carey - lisa_carey@med.unc.edu; Charles M Perou* - cperou@med.unc.edu

* Corresponding author
\end{abstract}

Published: 31 July 2007

BMC Genomics 2007, 8:258 doi:10.1/86/|47|-2/64-8-258
Received: 17 April 2007

Accepted: 31 July 2007

This article is available from: http://www.biomedcentral.com/I47I-2/64/8/258

(c) 2007 Hoadley et al; licensee BioMed Central Ltd.

This is an Open Access article distributed under the terms of the Creative Commons Attribution License (http://creativecommons.org/licenses/by/2.0), which permits unrestricted use, distribution, and reproduction in any medium, provided the original work is properly cited.

\begin{abstract}
Background: The epidermal growth factor receptor (EGFR/HERI) and its downstream signaling events are important for regulating cell growth and behavior in many epithelial tumors types. In breast cancer, the role of EGFR is complex and appears to vary relative to important clinical features including estrogen receptor (ER) status. To investigate EGFR-signaling using a genomics approach, several breast basal-like and luminal epithelial cell lines were examined for sensitivity to EGFR inhibitors. An EGFR-associated gene expression signature was identified in the basal-like SUMI02 cell line and was used to classify a diverse set of sporadic breast tumors.

Results: In vitro, breast basal-like cell lines were more sensitive to EGFR inhibitors compared to luminal cell lines. The basal-like tumor derived lines were also the most sensitive to carboplatin, which acted synergistically with cetuximab. An EGFR-associated signature was developed in vitro, evaluated on 24I primary breast tumors; three distinct clusters of genes were evident in vivo, two of which were predictive of poor patient outcomes. These EGFR-associated poor prognostic signatures were highly expressed in almost all basal-like tumors and many of the HER2+/ER- and Luminal B tumors.

Conclusion: These results suggest that breast basal-like cell lines are sensitive to EGFR inhibitors and carboplatin, and this combination may also be synergistic. In vivo, the EGFR-signatures were of prognostic value, were associated with tumor subtype, and were uniquely associated with the high expression of distinct EGFR-RAS-MEK pathway genes.
\end{abstract}




\section{Background}

The epidermal growth factor receptor (EGFR/HER1) is a member of the human epidermal growth factor receptor (HER) family of transmembrane receptor tyrosine kinases that is linked to growth control, cell adhesion, mobility, and apoptosis [1]. EGFR is an important regulator of epithelial cell biology, but its function in breast tumors is complicated by the observation that its function may vary according to important clinical features like estrogen receptor (ER) and HER2 status. Microarray studies have identified several subtypes of breast cancer arising from at least two different epithelial cell types [2-5]. Two of the molecular subtypes of breast cancer are partly defined by the high expression of ER, while a third is partly defined by the genomic DNA amplification and high expression of HER2 (i.e. HER2+/ER-, see [5]). The basal-like subtype has low expression of both ER and HER2, however, most basal-like tumors highly express EGFR as assessed by both gene and protein expression [6].

High expression of EGFR has been reported in a variety of epithelial tumors [7], leading to the development of drugs directed against this receptor $[8,9]$. One of these targeting strategies employs monoclonal antibodies (cetuximab) that bind the extracellular ligand-binding domain, while other strategies include small molecule inhibitors (gefitinib and erlotinib) that compete with ATP for binding to the intracellular tyrosine kinase domain [10-12]. In nonsmall cell lung cancer and breast cancer cell lines, it has been shown that some small molecule EGFR inhibitors increase cell killing when used in combination with chemotherapeutics $[13,14]$; therefore, the interactions between EGFR inhibitors and cytotoxic agents represent a promising combination for the future treatment of epithelial tumors that are dependent upon EGFR-signaling.

The lack of clinical response in breast cancers treated with gefitinib in vivo has been partially attributed to activation of this pathway downstream of EGFR, or ineffective methods of identifying those tumors that show an EGFRdependent signature. EGF independent activation of the EGFR-pathway via the PI3K/AKT pathway may occur through either loss of PTEN or mutation/activation of PI3K, both of which have been linked to gefitinib resistance [15-17]. Others have suggested that the MEK/ERK pathway may play a more important role in resistance to EGFR inhibitors [18-20]. Recently, Moyano et al. identified $\alpha \mathrm{B}$-Crystallin (CRYAB) as a protein that can constitutively activate the MEK/ERK pathway in breast epithelial cells and caused a cell line to become EGF independent [21].

In this study, we hypothesized that the breast tumor "intrinsic" subtypes might vary in dependence upon EGFR-signaling, which could be reflective of differences in gene expression patterns. Therefore, we used breast cell lines to identify an EGFR-pathway associated profile and examined interactions between EGFR inhibitors and cytotoxic chemotherapeutics in vitro. These analyses identified multiple EGFR-associated profiles in vivo that were of prognostic significance, showed important links with tumor subtype, and highlight potential downstream activators of the EGFR-RAS-MEK pathway.

\section{Results \\ Cell line models of breast cancer}

Breast cancer is a heterogeneous disease arising from at least two distinct epithelial cell populations, therefore, we selected cell lines models of basal-like and luminal cells to begin our investigations of the EGFR-pathway. The MCF7 and ZR-75-1 cell lines were derived from breast tumors of luminal origin and have expression of CK8/18 and ER. Our previous studies examining cell lines of basal-like origin used immortalized human mammary epithelial cell lines (HMECs) [22,23]; however, these lines are derived from normal rather than tumor tissue. Two ER-negative and HER2-non-amplified tumor-derived cell lines, SUM149 and SUM102, have been previously shown to express EGFR $[18,24]$ and show basal-like expression profiles [25]. The SUM102 and SUM149 lines share many characteristics with the basal-like tumors including expression of CK5/6, therefore, we included these two tumor-derived lines as in vitro models of basal-like breast cancers. By microarray analysis, EGFR gene expression was low in the luminal cell lines and higher in the basal-like lines. EGFR protein expression by Western blot analysis was detectable in the basal-like lines, but not in the luminal lines (data not shown).

\section{Drug sensitivity assays}

To assess EGFR inhibitor sensitivity, the six cell lines described above were treated for $72 \mathrm{~h}$ with a range of doses of gefitinib or cetuximab and a MTT assay was used to determine IC50 doses (Table 1). In response to gefitinib, the basal-like tumor-derived cell lines (SUM149 and SUM102) were two- to 100 -fold more sensitive than the luminal lines. The two immortalized HMEC lines were 33- and 50-fold more sensitive to gefitinib than the luminal lines, suggesting that the basal-like cell lines as a whole were more sensitive to gefitinib versus the luminal cell lines. Cetuximab sensitivity was observed in only a single cell line (SUM102, IC50 $=2 \mathrm{ug} / \mathrm{ml}$ ), with IC50 doses for MCF-7, ZR-75-1, SUM149, ME16C2, and HMECC not achievable even with cetuximab doses as high as $100 \mathrm{ug} / \mathrm{ml}$. These cell lines were also treated with inhibitors that affect targets downstream of EGFR in the pathway including U1026 (MEK1/2 inhibitor) and LY294002 (PI3K inhibitor). Most of the cell lines had a similar level of sensitivity to U0126 with the exception that SUM102 was approximately 5 -fold more sensitive. IC50 doses for 
Table I: Estimated IC50 doses of breast cell lines treated with EGFR, MEK, and PI3K inhibitors

\begin{tabular}{lcccc}
\hline Cell Line & Gefitinib $(\mu \mathrm{M})$ & Cetuximab $(\mu \mathrm{g} / \mathrm{mL})$ & U0I26 (uM) & LY294002 (uM) \\
\hline MEI6C & $0.3(0.02)$ & $>100^{\mathrm{a}}$ & $19.7(0.66)$ & $21.2(0.63)$ \\
HME-CC & $0.2(0.01)$ & $>100^{\mathrm{a}}$ & $12.7(0.33)$ & $7.3(0.17)$ \\
SUMI02 & $0.1(0.002)$ & $2.3(0.15)$ & $4.3(0.20)$ & $3.4(0.10)$ \\
SUMI49 & $4.7(0.14)$ & $>100^{\mathrm{a}}$ & $21.8(0.80)$ & $18.4(0.48)$ \\
MCF-7 & $21.1(0.29)$ & $>100^{\mathrm{a}}$ & $17.0(1.15)$ & $3.9(0.13)$ \\
ZR-75-I & $11.1(0.12)$ & $>100^{\mathrm{a}}$ & $25.0(0.74)$ & $2.4(0.05)$ \\
\hline
\end{tabular}

$72 \mathrm{~h} \mathrm{IC50}$ doses were calculated for the EGFR inhibitors gefitinib, cetuximab, the MEKI/2 inhibitor U0 I26, and the PI3K inhibitor LY294002.

Note that the standard errors are presented within ()

aNo achievable IC50 dose with doses up to $100 \mu \mathrm{g} / \mathrm{mL}$

LY294002 were similar for most lines with the exception of ME16C and SUM149 cells, which were approximately 5 -fold more resistant than the other lines. The SUM102 line was the only cell line that was sensitive to all four inhibitors and has previously been shown to be EGFRdependent [24], and thus, was chosen for further analyses of the EGFR pathway.

\section{Drug combination analyses}

Given the observation that most biologically targeted drugs like cetuximab typically show low response rates when tested in vivo alone, we examined the effects of chemotherapeutics (carboplatin, doxorubicin, 5-fluorouracil, and paclitaxel) as single agents across all cell lines and the combination of cetuximab plus chemotherapeutics in SUM102 cells. Note, we only used the SUM102 cells for the combination studies because they were the only cell line tested for which an IC50 dose for single agent cetuximab could be obtained. We also tested the combined effects of gefitinib, U0126, and LY294002 with chemotherapeutic agents in SUM102 cells. First, individual drug sensitivity (IC50 doses) for each chemotherapeutic was determined for all six cell lines (Table 2). The relative sensitivities varied across the cell lines and did not appear to correlate with cell type (i.e. basal-like vs. luminal), with the exception that the two basal-like tumorderived cell lines (SUM102 and SUM149) were at least three-fold more sensitive to carboplatin, and at least twofold more resistant to 5-fluorouracil when compared to their immortalized HMEC counterparts or the luminal cell lines.

As a starting point for combination experiments, we treated SUM102 cells for $72 \mathrm{~h}$ with cetuximab and a chemotherapeutic simultaneously. Synergistic interactions were not evident in any combination and all combinations were antagonistic as assessed by the method of Chou and Talalay in CalcuSyn [26] (Figure 1). We next analyzed the effect of sequential treatment: cells were treated for (a) $72 \mathrm{~h}$ with cetuximab followed by $72 \mathrm{~h}$ with chemotherapy, (b) $72 \mathrm{~h}$ with chemotherapy followed by $72 \mathrm{~h}$ with cetuximab, or (c) with cetuximab and chemotherapy simultaneously for $144 \mathrm{~h}$. Chemotherapy followed by cetuximab was generally more growth inhibitory than cetuximab followed by chemotherapy (Figure 1). The one exception was cetuximab with paclitaxel, where all sequence combinations were antagonistic (Figure 1). However, this antagonism may result from the high sensitivity to paclitaxel already observed in the SUM102 line (Table 2). Carboplatin followed by cetuximab and the $144 \mathrm{~h}$ concurrent treatments were synergistic even at low doses of both drugs. 5-fluorouracil followed a similar trend to that of carboplatin, while in the doxorubicin combinations synergy was only evident at doses higher than the IC50 dose for doxorubicin first, or the 144 h concurrent (Figure 1). Similar results were observed for combinations with gefitinib and LY294002 (a PI3K inhibitor) where chemotherapy followed by each inhibitor, and the $144 \mathrm{~h}$ concurrent treatments, were more effective

Table 2: Estimated IC50 doses of breast cell lines treated with chemotherapeutics

\begin{tabular}{lcccc}
\hline Cell Line & 5-Florouracil (uM) & Doxorubicin (nM) & Carboplatin (uM) & Paclitaxel (nM) \\
\hline MEI6C & $6.0(0.29)$ & $32.8(1.89)$ & $37.5(0.63)$ & $0.052(0.004)$ \\
HME-CC & $1.1(0.07)$ & $35.5(3.26)$ & $48.3(1.41)$ & $0.025(0.003)$ \\
SUMI02 & $16.8(0.82)$ & $5.1(0.27)$ & $11.7(0.26)$ & $0.00057(0.00001)$ \\
SUMI49 & $28.6(1.33)$ & $45.0(3.06)$ & $7.7(0.24)$ & $0.71(0.006)$ \\
MCF-7 & $1.2(0.15)$ & $56.9(4.26)$ & $89.4(3.79)$ & $0.23(0.02)$ \\
ZR-75-I & $8.4(1.06)$ & $26.5(1.39)$ & $62.6(1.98)$ & $0.99(3.34)$ \\
\hline
\end{tabular}

Note that the standard errors are presented within (). 
A

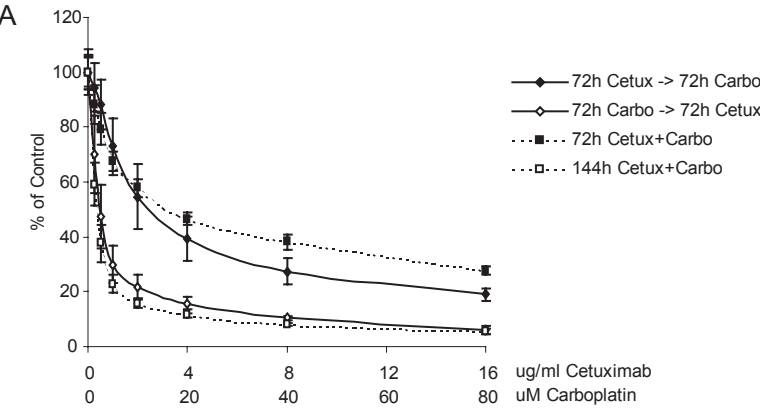

C

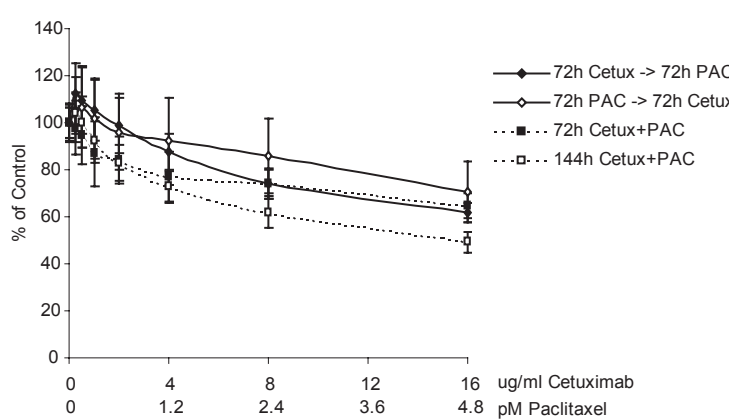

E

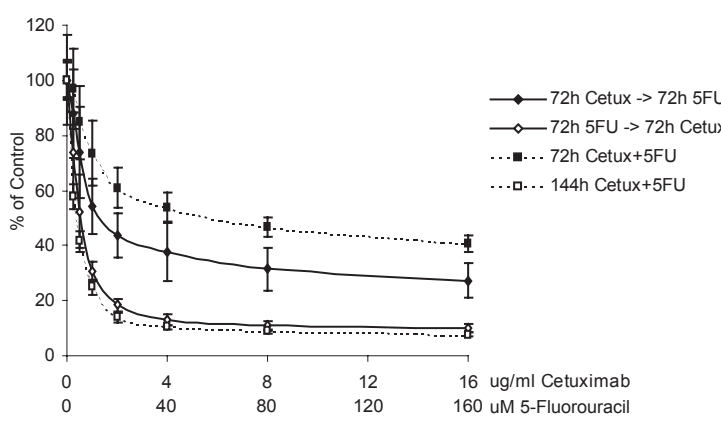

G

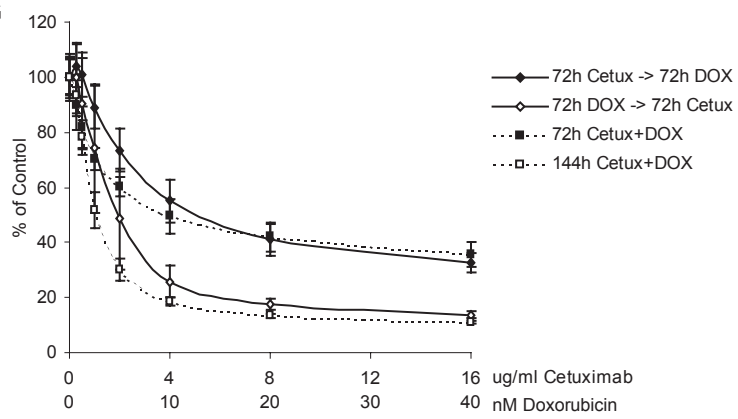

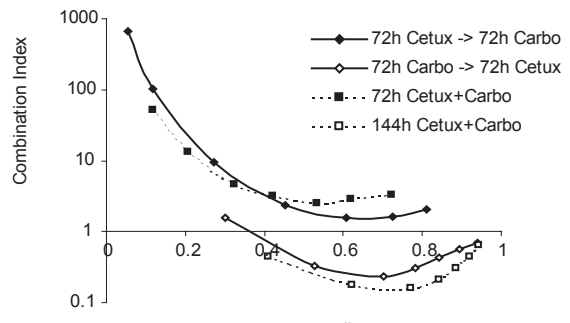

Fraction Affected

D

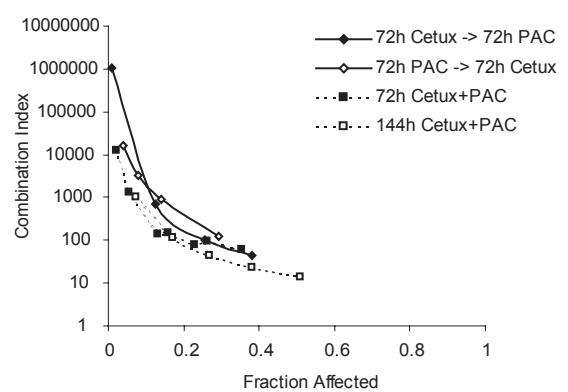

$\mathrm{F}$
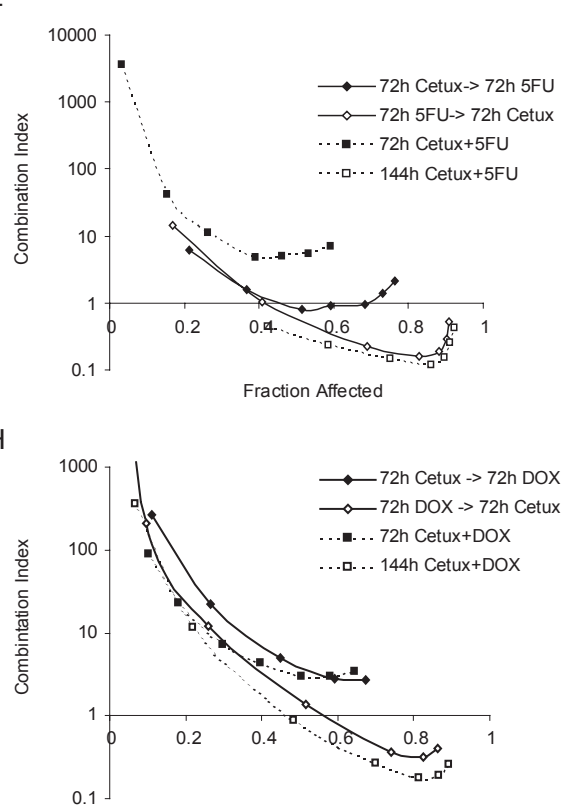

Fraction Affected

\section{Figure I}

Effects of different combination schedules of cetuximab with chemotherapeutics in SUMI 02 cells. Cells were treated with four different combination schedules: I) $72 \mathrm{~h}$ cetuximab followed by $72 \mathrm{~h}$ chemotherapy, 2) $72 \mathrm{~h}$ chemotherapy followed by $72 \mathrm{~h}$ cetuximab, 3) $72 \mathrm{~h}$ concurrent chemotherapy and cetuximab, and 4) I $44 \mathrm{~h}$ concurrent chemotherapy and cetuximab. A) Growth inhibitory effects of cetuximab and carboplatin combinations. B) Combination analysis of cetuximab and carboplatin treatments. C) Growth inhibitory effects of cetuximab and paclitaxel combinations. D) Combination analysis of cetuximab and paclitaxel treatments. E) Growth inhibitory effects of cetuximab and 5-fluorouracil combinations. F) Combination analysis of cetuximab and 5-fluorouracil treatments. G) Growth inhibitory effects of cetuximab and doxorubicin combinations. H) Combination analysis of cetuximab and doxorubicin treatments. Combination Index $(\mathrm{Cl})$ values below one are synergistic, equal to one are additive, and greater than one are antagonistic. 
than the biological inhibitor first (data not shown). Synergy was also observed in SUM149 in addition to SUM102 for combinations of gefitinib and carboplatin (see Additional file 1). U0126 (a MEK inhibitor) combinations exhibited different results and chemotherapeutics given first followed by U0126 were slightly less synergistic than the U0126 first or concurrent treatment; however, for U0126, all combinations except doxorubicin first, or paclitaxel first, were synergistic (data not shown).

\section{EGFR-associated gene expression patterns in vitro}

To identify an EGFR-pathway associated profile, we analyzed the gene expression data of the SUM102 cell line treated with EGFR inhibitors (baseline) and then released from this inhibition to identify those genes that were induced upon removal of the inhibitor. Using an unsupervised analysis, we hierarchically clustered all time points from the cetuximab and gefitinib treatment experiments and identified over 500 genes that changed in expression at least 4 -fold (Figure 2). Even though the two EGFR inhibitors have different mechanisms of inhibition, SUM102 cells treated for $48 \mathrm{~h}$ with gefitinib or cetuximab showed very similar gene expression patterns. Intra-class correlation (ICC) values between the gefitinib and cetuximab treated samples ranged from 0.627 to 0.934 , and this level of similarity is evident in the short dendrogram branches from the cluster analysis (Figure 2B). The post treatment samples (i.e. after removal of inhibitor) that represent the reactivation of the EGFR-pathway were even more similar (ICC within each time point ranged from 0.862 to 0.962 ). A two-class SAM analysis to look for differences between gefitinib-post treatment samples versus cetuximab-post treatment samples identified only 58 significantly different genes with a false discovery rate (FDR) of 5\%; thus, from a transcription standpoint, gefitinib and cetuximab elicited very similar results in SUM102 cells.

In response to gefitinib and cetuximab, the SUM102 cell line exhibited decreased expression of many proliferation genes (Figure 2). There was also a large cluster of genes that were induced by the inhibitors, consisting predominately of hypothetical genes with unknown functions. We were more interested in the genes induced after the removal of the inhibitor as this reflects the gene expression patterns associated with the reactivation of the EGFR pathway. As early as $4 \mathrm{~h}$ and $8 \mathrm{~h}$ after inhibitor removal there was a substantial increase in expression for two ligands of EGFR, namely amphiregulin and epiregulin. Cyclin A1 was also substantially increased (Figure 2C and 2D). Starting at $4 \mathrm{~h}$ and continuing through $8 \mathrm{~h}$ and $24 \mathrm{~h}$, genes with known roles in $\mathrm{G} 1 / \mathrm{S}$ phase such as $C D C 6, C D C 7$, TIMELESS, and ORCL6 were increased (Figure 2E and see Additional file 2). By $8 \mathrm{~h}$ and $24 \mathrm{~h}$, DNA synthesis and DNA damage checkpoint genes were induced (Figure 2F). Classical gene expression-defined proliferation genes including STK6 and Cyclin B1 were highly induced by 24 $\mathrm{h}$ (Figure 2G). There was also a repression of negative regulators of growth such as Growth arrest-specific 1 and Cyclin G2 (see Additional file 2).

\section{Role of MEK and PI3K in the in vitro EGFR-profile}

Activation of EGFR leads to the downstream activation of other signaling components including the MEK/ERK and PIK3/AKT pathways [1]. To examine the role of these effectors, we treated the SUM102 cell line with the MEK1/ 2 inhibitor U0126 and the PI3K inhibitor LY294002 alone, and in combination. Microarray time course experiments using inhibitor treated cells followed by inhibitor removal were conducted for U0126 and LY294002 similar what was done for the cetuximab and gefitinib experiments. The observed gene expression profiles for the U0126 and the LY294002 experiments were similar in both gene identity and direction when compared to the cetuximab/gefitinib profile, but gene expression changes were typically reduced in magnitude. The U0126 and LY294002 signatures when compared to each other were very similar at the $4 \mathrm{~h}$ and $8 \mathrm{~h}$ time points (average ICC = 0.83 ), but diverged at $24 \mathrm{~h}$ post treatment (average ICC $=$ $0.59)$. The gene expression signatures of LY294002 and U0126 samples were also correlated with the gefitinib/ cetuximab gene expression patterns at $4 \mathrm{~h}$ and $8 \mathrm{~h}$ post treatment (LY294002 compared to gefitinib/cetuximab ICC $=0.83$, U0126 compared to gefitinib/cetuximab ICC $=0.77$ ). The LY294002 and U0126 $24 \mathrm{~h}$ post treatment samples were less correlated with gefitinib/cetuximab 24 h post samples (LY294002 compared to gefitinib/cetuximab ICC $=0.51$, U0126 compared to gefitinib/cetuximab ICC $=0.41$ ). We also treated cells with LY294002 and U0126 simultaneously to determine if the combined treatment would more completely recapitulate the EGFRassociated profile; the $24 \mathrm{~h}$ post combined treatment samples showed a higher correlation value to the gefitinib/ cetuximab samples (average ICC $=0.73$ ), but still did not account for the entire gene expression pattern of the $24 \mathrm{~h}$ post cetuximab/gefitinib treatments. These results suggest that the cetuximab/gefitinib profile could not be simply attributed to either the MEK or PIK3 pathway, but that the combination of these two pathways was more representative of the EGFR-signature than either pathway alone.

\section{EGFR-associated gene expression patterns in vivo}

To identify an EGFR-associated in vivo signature, a oneclass SAM analysis was performed using the SUM102 cells to identify the genes that were statistically induced in the post treatment samples relative to the inhibitor treated samples. Adjusting the SAM delta value to obtain the largest gene set with less than 5\% FDR resulted in a gene list that was extremely large (10,017 genes, $4.97 \%$ FDR), therefore, the top 500 induced genes were selected for further analysis $(0.02 \%$ FDR). This gene list was next used to 


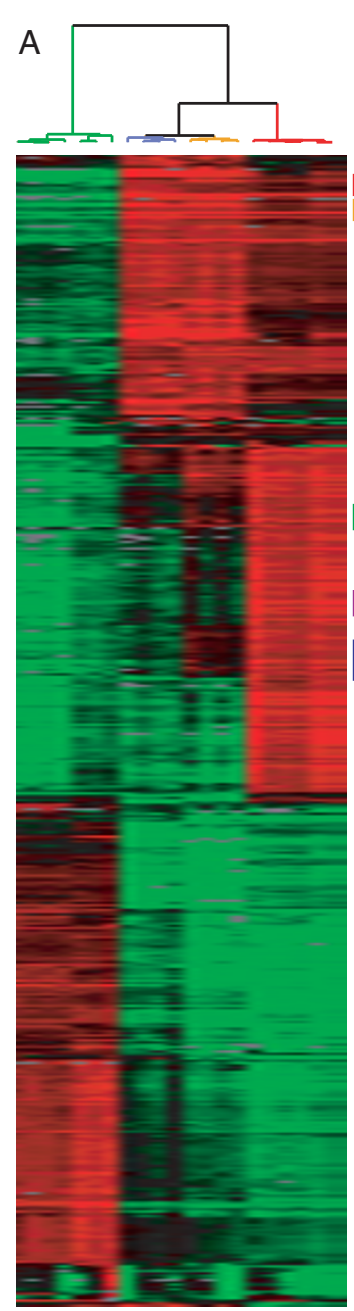

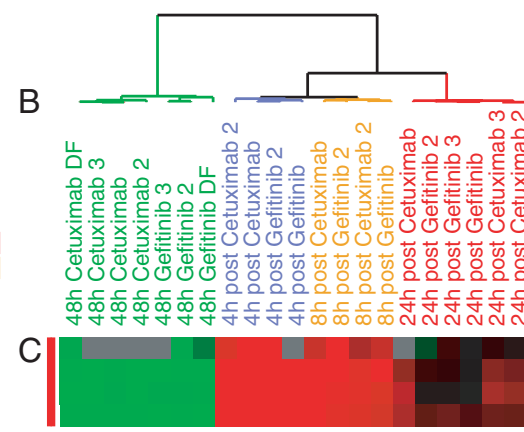
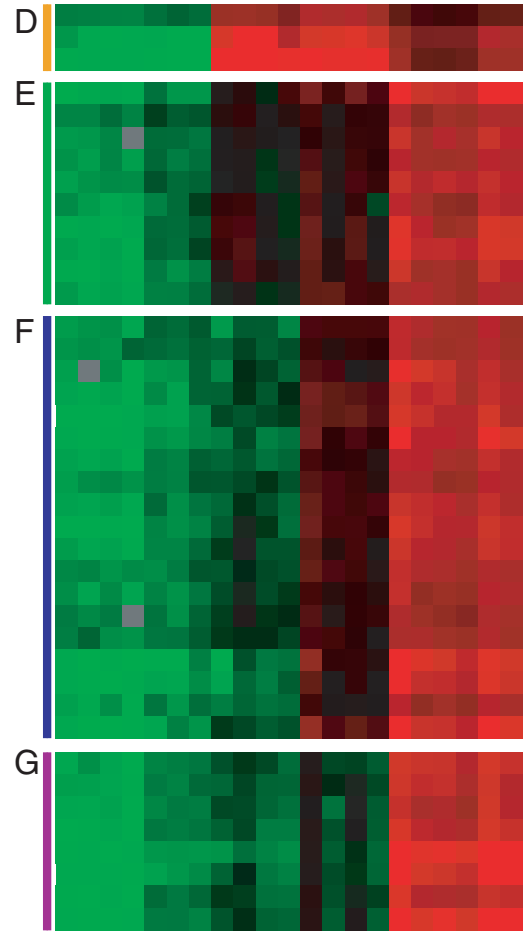

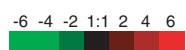

Chemokine ligand 20 NM_004591

Dual specificity phosphatase 6 NM 001946

Early growth response 1 NM_001964

Amphiregulin NM_001657

Serine or cysteine proteinase inhibitor, clade B, member 5 NM 002639

Cyclin A1 NM 003914

Epiregulin NM_001432

CDC28 protein kinase regulatory subunit 2 NM_001827

Sin3-associated polypeptide, 30kDa NM 003864

Hypothetical protein FLJ20647 NM $017 \overline{9} 18$

Deoxythymidylate kinase (thymidylate kinase) NM 012145

Timeless homalog NM 003920

Similar to Ubiquitin-conjugating enzyme E2S XM 496186

Ubiquitin-conjugating

Ubiquitin-conjugating enzyme E2S NM 0145

Hypothetical protein MGC40489 XM_37̄3742

CDC7 cell division cycle 7 NM 003503

Chromatin assembly factor 1, subunit A p150 NM_005483

Replication factor C activator 15, 36.5kDa NM_181578

Bloom syndrome NM 000057

WD repeat and HMG-box DNA binding protein 1 NM 001008396

Exonuclease 1 NM 130398

Ubiquitin-conjugating enzyme E2T (putative) NM 014176

Breast cancer 1 , early onset NM 007295

MCM5 NM 006739

Polymerase DNA-directed, alpha 70kD NM 002689

DNA replication complex GINS protein PSF2 NM 016095

Hypothetical protein FLJ10706 NM_018186

Proliferating cell nuclear antigen NM 002592

CHK1 checkpoint homolog NM_001274

RecQ protein-like 4 NM_004260

RecQ protein-like 4 NM_004260

Helicase, lymphoid-specific NM_018063

CDC45 cell division cycle 45-like NM_003504

Cell division cycle associated 5 NM_080668

RAD51 homolog (RecA homolog) NM 133487

Cyclin A2 NM_001237

Polo-like kinase 4 NM 014264

Cell division cycle associated 8 NM_018101

Serine/threonine kinase 6 NM_003600

Thymidylate synthetase NM 001071

DEP domain containing 1B BC019075

More than blood homolog NM 017760

Cyclin B1 NM_031966

\section{Figure 2}

Gene expression patterns for SUM 02 cells treated with gefitinib or cetuximab. Unsupervised hierarchical cluster analysis was performed on $48 \mathrm{~h}$ inhibitor treated and $4 \mathrm{~h}, 8 \mathrm{~h}$, and $24 \mathrm{~h}$ post $48 \mathrm{hr}$ inhibitor treated samples. A) The complete cluster overview with the colored bars indicating the location of the clusters shown in C-G. B) Close up of the experimental sample associated dendrogram. C+D) $4 \mathrm{~h}$ and $8 \mathrm{~h}$ post treatment induced genes including the EGFR ligands Amphiregulin and Epiregulin. E) Genes involved with the GI/S phase transition induced beginning in the $4 \mathrm{~h}$ post inhibitor and continuing though 24 h. F) Genes involved in DNA synthesis induced at $8 \mathrm{~h}$ post inhibitor and continuing through 24 h. G) Proliferation genes typically observed in tumor derived profiles including STK6 and Cyclin BI.

cluster 248 UNC breast tumor and normal samples representing all five breast tumor subtypes (Figure 3 and see Additional file 3). The list of induced genes from the in vitro SUM102 experiments were not homogenously expressed across the tumor samples; therefore, to study these multiple expression patterns in the tumors, we defined "clusters" as any gene set that contained a minimum of 20 genes and a Pearson node correlation greater than 0.55 . Using this criteria, we identified three clusters:
Cluster \# 1 was highly expressed in a mix of breast tumors that contained all five breast cancer subtypes: luminal A, luminal B, basal-like, HER2+/ER- and normal-like samples (Figure 3C, far right dendrogram branch, 35 genes); Cluster \#2 identified a set of tumors that contained 58\% of all basal-like tumors, 48\% of all HER2+/ER- tumors and 3 luminal B tumors (Figure 3D, center dendrogram branch, 27 genes); Cluster \#3 was highly enriched for luminal A and B tumors, and was also highly expressed in 


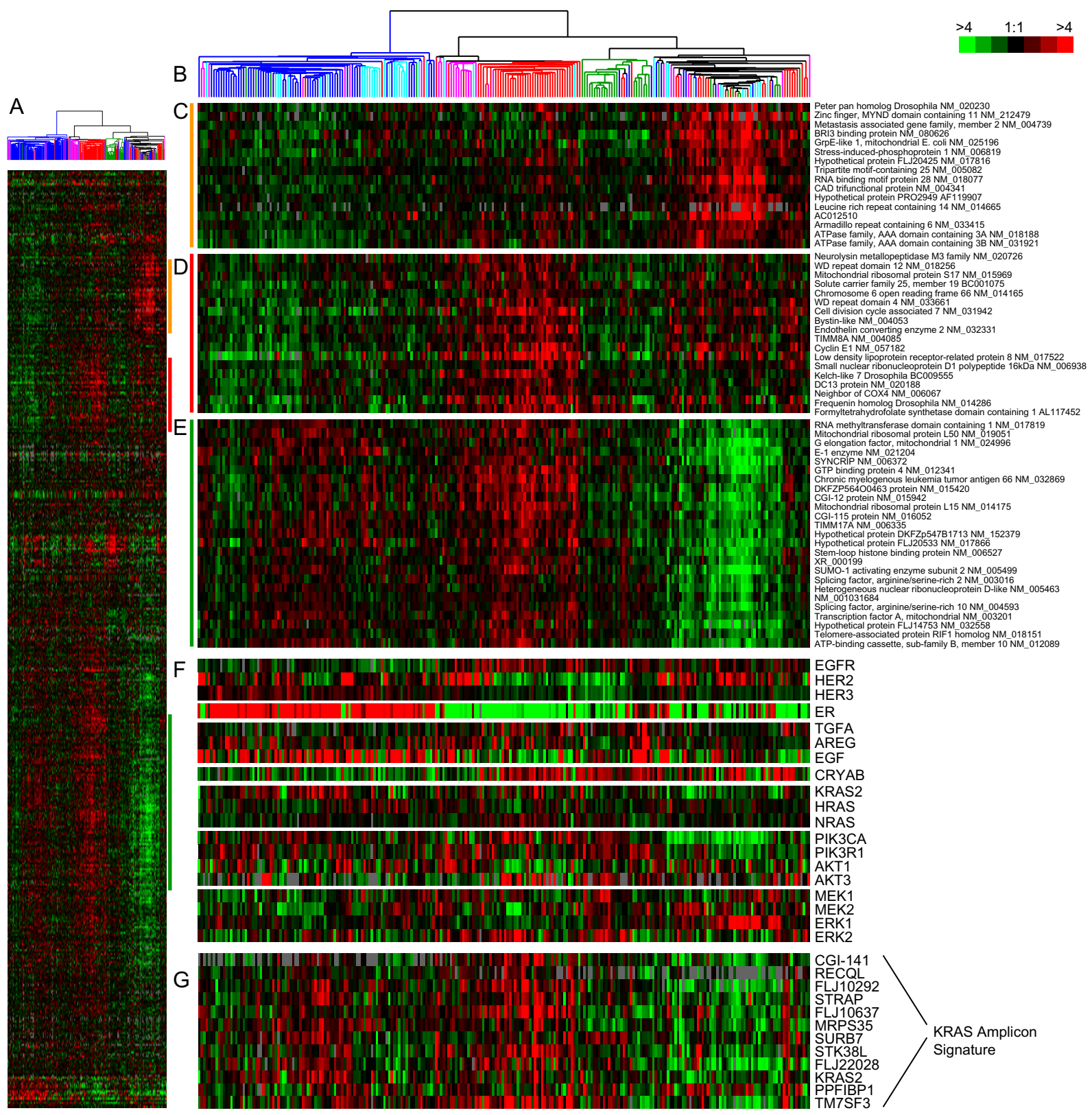

Figure 3

In vivo EGFR-associated profiles and additional genes implicated in the EGFR-RAS-MEK pathway. A) The top 500 induced genes from the SUMI02 post treatment experiments were hierarchical clustered using the 248 UNC tumors. Colored bars indicate the location of the three clusters in D-E. B) Tumor associated dendrogram color coded according to tumor subtype: Luminal A - dark blue, Luminal B - light blue, true normals and normal-like - green, HER2+/ER-negative - pink, and basal-like - red. C) Cluster \#I that identified a mixed group of tumors. D) Selected genes from the center of Cluster \#2 that are high in most basal-like tumors. E) Selected genes from the center of Cluster \#3 that are high in the luminal tumors. F) Data for genes with suggested roles in EGFR-pathway. G) Data for the KRAS-amplicon signature identified in Herschkowitz et al. [35]. 
Table 3: Multivariate Cox Proportional Hazards analysis of EGFR clusters with clinical parameters in NKI295 data set

\begin{tabular}{|c|c|c|c|c|}
\hline \multirow[b]{2}{*}{ Variable } & \multicolumn{2}{|c|}{$\underline{\text { Relapse Free Survival }}$} & \multicolumn{2}{|c|}{ Overall Survival } \\
\hline & Hazard Ratio $(95 \% \mathrm{Cl})$ & $\mathrm{p}$-value & Hazard Ratio $(95 \% \mathrm{Cl})$ & $\mathrm{p}$-value \\
\hline \multicolumn{5}{|c|}{ Standard clinical parameters } \\
\hline Age, per decade & $0.59(0.43-0.81)$ & 0.001 & $0.67(0.45-0.99)$ & 0.04 \\
\hline ER status & $0.64(0.42-0.98)$ & 0.04 & $0.45(0.27-0.7 I)$ & 0.0009 \\
\hline Size & $1.38(0.94-2.02)$ & 0.10 & $1.50(0.94-2.4 \mathrm{I})$ & 0.09 \\
\hline Tumor grade 2 vs. I & $2.4 \mid(1.3 \mid-4.43)$ & 0.005 & $4.30(1.48-12.35)$ & 0.007 \\
\hline Tumor grade 3 vs. I & $2.58(1.38-4.8 I)$ & 0.003 & $6.02(2.09-17.35)$ & 0.0009 \\
\hline Nodes I-3 vs. 0 & $0.85(0.55-1.32)$ & 0.48 & $0.91(0.53-1.56)$ & 0.72 \\
\hline Nodes $>3$ vs. 0 & $1.37(0.83-2.26)$ & 0.22 & $1.56(0.85-2.85)$ & 0.14 \\
\hline \multicolumn{5}{|c|}{ Standard clinical parameters and Cluster \#I } \\
\hline Age, per decade & $0.59(0.43-0.82)$ & 0.002 & $0.67(0.45-0.99)$ & 0.05 \\
\hline ER status & $0.67(0.43-1.04)$ & 0.08 & $0.45(0.27-0.75)$ & 0.002 \\
\hline Size & $1.35(0.92-1.99)$ & 0.12 & I.48 (0.92-2.39) & 0.11 \\
\hline Tumor grade 2 vs. I & $2.26(1.23-4.18)$ & 0.009 & $4.13(1.42-11.98)$ & 0.009 \\
\hline Tumor grade 3 vs. I & $2.21(1.16-4.22)$ & 0.02 & $5.34(1.81-17.74)$ & 0.002 \\
\hline Nodes I-3 vs. 0 & $0.82(0.56-1.27)$ & 0.38 & $0.86(0.50-1.50)$ & 0.60 \\
\hline Nodes $>3$ vs. 0 & $1.23(0.73-2.06)$ & 0.43 & $1.46(0.79-2.71)$ & 0.23 \\
\hline Cluster \#I med vs. low & $1.53(0.93-2.53)$ & 0.10 & $1.25(0.65-2.39)$ & 0.50 \\
\hline Cluster \#I high vs. low & $1.70(1.01-2.88)$ & 0.05 & $1.43(0.76-2.69)$ & 0.27 \\
\hline \multicolumn{5}{|c|}{ Standard clinical parameters and Cluster \#2 } \\
\hline Age, per decade & $0.60(0.43-0.83)$ & 0.002 & $0.67(0.452-0.99)$ & 0.04 \\
\hline ER status & $0.73(0.46-1.16)$ & 0.18 & $0.54(0.32-0.91)$ & 0.02 \\
\hline Size & I.4I (0.96-2.07) & 0.08 & $1.52(0.94-2.44)$ & 0.09 \\
\hline Tumor grade 2 vs. I & $1.94(1.05-3.61)$ & 0.04 & $3.36(1.15-9.83)$ & 0.03 \\
\hline Tumor grade 3 vs. I & $1.74(0.90-3.37)$ & 0.10 & $3.54(1.20-10.73)$ & 0.02 \\
\hline Nodes I-3 vs. 0 & $0.80(0.52-1.23)$ & 0.31 & $0.81(0.47-1.39)$ & 0.44 \\
\hline Nodes $>3$ vs. 0 & $1.19(0.7 \mathrm{I}-1.98)$ & 0.51 & $1.36(0.74-2.49)$ & 0.32 \\
\hline Cluster \#2 med vs. low & $2.13(1.22-3.7 I)$ & 0.008 & $2.10(0.95-4.64)$ & 0.07 \\
\hline Cluster \#2 high vs. low & $2.63(1.44-4.79)$ & 0.002 & $3.46(1.58-7.59)$ & 0.002 \\
\hline \multicolumn{5}{|c|}{ Standard clinical parameters and Cluster \#3 } \\
\hline Age, per decade & $0.58(0.42-0.8 I)$ & 0.001 & $0.67(0.45-0.98)$ & 0.04 \\
\hline ER status & $0.68(0.43-1.07)$ & 0.10 & $0.45(0.27-0.76)$ & 0.003 \\
\hline Size & $1.39(0.95-2.03)$ & 0.10 & I.49 (0.93-2.4I) & 0.10 \\
\hline Tumor grade 2 vs. I & $2.30(1.24-4.24)$ & 0.008 & $4.13(1.42-12.00)$ & 0.009 \\
\hline Tumor grade 3 vs. I & $2.29(1.20-4.38)$ & 0.01 & $5.38(1.83-\mid 5.80)$ & 0.002 \\
\hline Nodes I-3 vs. 0 & $0.83(0.54-1.29)$ & 0.41 & $0.86(0.50-1.49)$ & 0.60 \\
\hline Nodes $>3$ vs. 0 & $1.30(0.79-2.16)$ & 0.31 & I.47 (0.80-2.70) & 0.22 \\
\hline Cluster \#3 med vs. low & $1.32(0.8 \mathrm{I}-2.16)$ & 0.26 & $1.54(0.80-2.95)$ & 0.20 \\
\hline Cluster \#3 high vs. low & 1.41 (0.84-2.37) & 0.19 & $1.43(0.73-2.78)$ & 0.29 \\
\hline
\end{tabular}

Age was a continuous variable grouped in decade years, size was a binary variable $(0=<2 \mathrm{~cm}, \mathrm{I}=>2 \mathrm{~cm})$, tumor grade 2 and 3 are relative to grade $\mathrm{I}$, and node status ( $1-3$ nodes or $>3$ nodes) was relative to 0 positive nodes. Expression of the three clusters was averaged, rank ordered, divided into equal thirds; medium and high expression is relative to low expression. Significant variables are displayed in bold.

most of the HER2+/ER- and basal-like tumors that were also high for Cluster \#2 (Figure 3E, left dendrogram branch- luminal A and B tumors, and center dendrogram branch - HER2+/ER- and basal tumors, 139 genes). Thus each gene cluster could represent a distinct EGFR-associated signature that is enriched in different subsets of tumors (for full gene lists for each cluster see Additional File 4). Gene Ontology (GO) analysis using EASE was performed on each gene cluster but only Cluster \#3 had any significant GO terms, which were RNA processing, metabolism, binding, splicing, and modification (EASE scores < 0.05). Cyclin E1 was present within Cluster \#2 and is a known prognostic marker for breast cancer patients [27]; Cyclin E1 is also associated with basal-like breast cancers
$[28,29]$, which was recapitulated here. Lastly, Cyclin E1 is known to be regulated by EGFR-signaling [30], where both AKT and ERK can inhibit p27kip1, which is a negative regulator of CDK2/Cyclin E1 complex [31,32].

To further examine the biological importance of these three EGFR-associated gene sets, we individually applied them to a test set of breast tumors (i.e. the NKI295 sample set described in $[33,34])$ and determine whether they predicted patient outcomes. First, we determined a mean expression value of all genes within each cluster for each patient. Next, the patients were rank-ordered according to their mean expression values for each cluster and divided into halves or thirds. Kaplan-Meier survival analyses for 
Relapse-Free Survival (RFS) and Overall Survival (OS) were performed and all three clusters were statistically significant predictors of outcomes where high expression always predicted a poor outcome (Figure 4 - OS; data not shown for RFS). High expression of clusters \#2 and \#3 were also significant predictors of RFS and OS in the UNC training data set (data not shown). Using a Cox regression analysis, we tested each cluster with the standard clinical parameters and determined that the high expression (top third) of Cluster \#2 compared to the lowest expression (bottom third) significantly predicted a worse outcome for both RFS and OS (Table 3) after controlling for age, ER status, size, grade, and node status. Since the NKI295 data set was enriched for node-negative tumors less than $5 \mathrm{~cm}$ in diameter, tumor size and node status were not significant in the multivariate analysis [33,34]. Chi-squared analyses were performed to identify relations between tumor subtypes and Clusters \#1-3. Consistent with observations from Figure 3, the basal-like, luminal $\mathrm{B}$, and HER2+/ER- tumors were associated with the high expression of all three clusters while the luminal A and normallike samples rarely showed high expression (Table $4, \mathrm{p}=<$ $0.0001)$; in particular, the majority of basal-like tumors were almost all high for Cluster \#2 (89\% in top $1 / 3)$.

\section{Analysis of EGFR-pathway components relative to expression patterns in vivo}

Since most of the genes from the in vivo focused EGFRassociated signatures were not established members of the HER-signaling pathway, we examined the gene expression patterns of many of the known pathway components for their ability to predict patient outcomes, and determined if they showed correlations to any of the EGFR-associated profiles. Gene expression data for three-fourths of the HER family of receptors (EGFR, HER2, HER4), some of their ligands (TGFA, EGF, AREG), as well as other pathway components including MEK1, MEK2, PIK3CA, PIK3R1, $C R Y A B, A K T 1-3$, the RAS proteins $(\mathrm{H}, \mathrm{K}$ and $\mathrm{N}), E R K 1$, $E R K 2$, and a KRAS-amplicon signature (identified and defined in Herschkowitz et al. [35]), were individually tested for the ability to predict patient outcomes, for correlations with tumor subtype (Table 4), and for correlations with the EGFR-associated expression Clusters \#1-3 (Table 5). Gene expression for individual genes was rankorder and divided into thirds as was done for Clusters \#13 previously, and each gene was tested for its ability to predict outcomes in the UNC 248 and NKI 295 tumor data sets. No individual gene's expression pattern listed above significantly predicted RFS and OS in both the UNC and NKI data sets.
Cluster 1
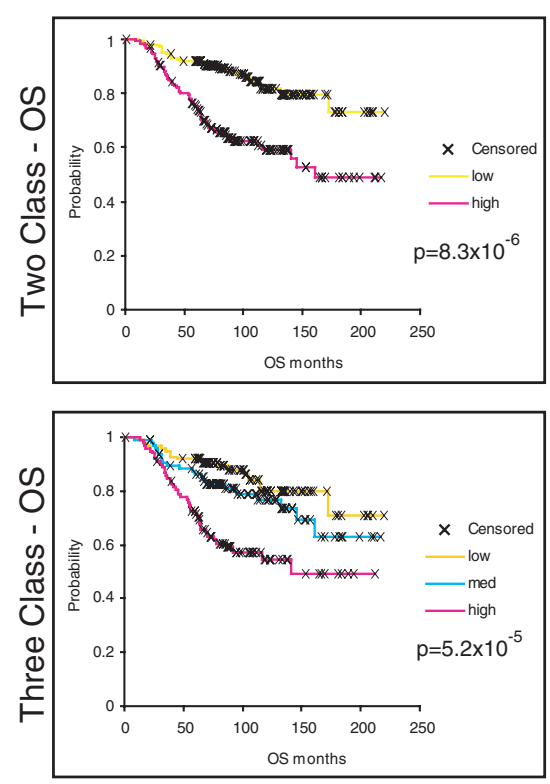

Cluster 2
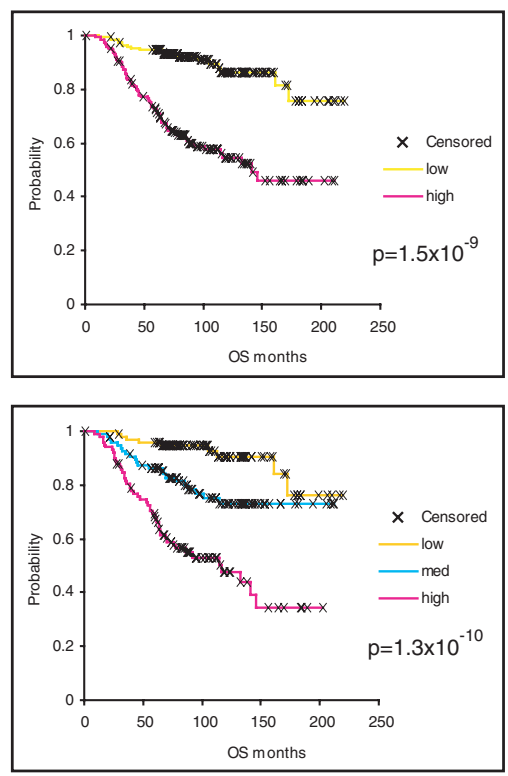

Cluster 3
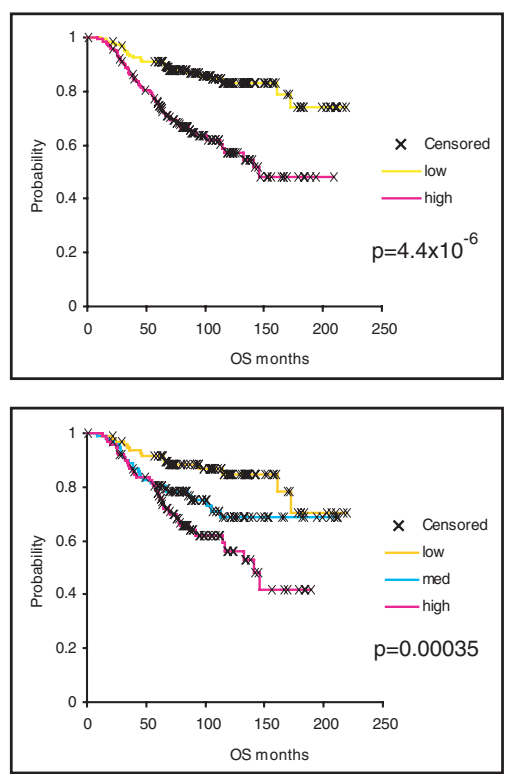

Figure 4

Kaplan-Meier survival plots for the 295 NKI tumors/patients using the in vivo defined EGFR-associated profiles. The average expression value for each cluster in each patient was determined and the patients then put into rank-order and divided into two equal groups or three equal groups. Overall survival analysis was performed for each cluster. $\mathrm{X}$ indicates censored data due loss to follow-up or to information at last checkup. Note that Clusters \#2 and \#3 were also similarly prognostic for the UNC 248 training data set. 
Table 4: Chi-square analysis for association of gene expression with subtypes

\begin{tabular}{|c|c|c|c|c|c|c|}
\hline & Basal-like & HER2+/ER- & Luminal A & Luminal B & Normal-like & P-value \\
\hline \# tumors & 53 & 35 & 123 & 55 & 29 & \\
\hline Cluster $\left.\right|^{a}$ & $68 \%$ & $37 \%$ & $12 \%$ & $56 \%$ & $14 \%$ & $<0.0001$ \\
\hline Cluster $2^{\mathrm{a}}$ & $89 \%$ & $49 \%$ & $5 \%$ & $49 \%$ & $7 \%$ & $<0.0001$ \\
\hline Cluster $3^{a}$ & $77 \%$ & $51 \%$ & $11 \%$ & $47 \%$ & $0 \%$ & $<0.0001$ \\
\hline EGFR $^{\mathrm{a}}$ & $68 \%$ & $20 \%$ & $27 \%$ & $18 \%$ & $41 \%$ & $<0.0001$ \\
\hline HER ${ }^{\mathrm{a}}$ & $15 \%$ & $100 \%$ & $28 \%$ & $26 \%$ & $24 \%$ & $<0.0001$ \\
\hline HER4* & $9 \%$ & $3 \%$ & $50 \%$ & $38 \%$ & $31 \%$ & $<0.0001$ \\
\hline TGFA $^{b}$ & $74 \%$ & $37 \%$ & $17 \%$ & $25 \%$ & $38 \%$ & $<0.0001$ \\
\hline AREGa & $3 \%$ & $34 \%$ & $43 \%$ & $35 \%$ & $41 \%$ & $<0.0001$ \\
\hline EGF & $17 \%$ & $40 \%$ & $37 \%$ & $36 \%$ & $31 \%$ & 0.23 \\
\hline CRYABa & $70 \%$ & $11 \%$ & $33 \%$ & $4 \%$ & $48 \%$ & $<0.0001$ \\
\hline KRAS amplicon ${ }^{\mathrm{a}}$ & $68 \%$ & $40 \%$ & $24 \%$ & $35 \%$ & $0 \%$ & $<0.0001$ \\
\hline KRAS gene ${ }^{c}$ & $32 \%$ & $37 \%$ & $33 \%$ & $38 \%$ & $21 \%$ & 0.36 \\
\hline HRASd & $32 \%$ & $66 \%$ & $17 \%$ & $64 \%$ & $7 \%$ & $<0.0001$ \\
\hline NRASa & $70 \%$ & $28 \%$ & $17 \%$ & $44 \%$ & $21 \%$ & $<0.0001$ \\
\hline PIK $3 C A$ & $30 \%$ & $17 \%$ & $36 \%$ & $36 \%$ & $41 \%$ & 0.28 \\
\hline PIK3R Ia & $21 \%$ & $14 \%$ & $42 \%$ & $25 \%$ & $55 \%$ & 0.0012 \\
\hline AKTIa & $26 \%$ & $63 \%$ & $27 \%$ & $40 \%$ & $24 \%$ & $<0.0001$ \\
\hline AKT2* & $26 \%$ & $40 \%$ & $27 \%$ & $47 \%$ & $38 \%$ & 0.26 \\
\hline $\mathrm{AKT}^{\mathrm{a}}$ & $51 \%$ & $14 \%$ & $39 \%$ & $9 \%$ & $45 \%$ & $<0.0001$ \\
\hline MEKI & $53 \%$ & $46 \%$ & $25 \%$ & $29 \%$ & $24 \%$ & 0.023 \\
\hline MEK2 ${ }^{\mathrm{e}}$ & $42 \%$ & $43 \%$ & $25 \%$ & $42 \%$ & $24 \%$ & 0.068 \\
\hline ERKIf & $30 \%$ & $26 \%$ & $31 \%$ & $42 \%$ & $41 \%$ & 0.49 \\
\hline ERK $2 \mathrm{~g}$ & $40 \%$ & $31 \%$ & $26 \%$ & $45 \%$ & $31 \%$ & 0.048 \\
\hline
\end{tabular}

Samples were rank ordered into three equal groups and the percentage of each subtype in the highest expression group is reported for the NKI patient data set.

*Note: HER4 could not be assessed in UNC data due to too many missing values; HER3 was not present in the NKI data set; AKT2 was not present in the UNC data set

a associations were also similarly significant in the UNC sample set

$\mathrm{b}$ nominally significant in UNC data $(\mathrm{p}$-value $=0.0046)$

${ }^{c}$ nominally significant association in the UNC data $(p-v a l u e=0.005 \mathrm{I})$

$d$ nominally significant in the UNC data ( $p$-value $=0.003$ )

e nominally significant in the UNC data $(p$-value $=0.0023)$

${ }^{f}$ significant in the UNC data ( $p$-value $\left.=0.0003\right)$

$g$ significant in the UNC data ( $\mathrm{p}$-value $=<0.000 \mathrm{I})$

Bonferroni corrected level of significance $\alpha=0.0022$

Associations of genes or clusters with intrinsic subtype were examined using Chi-square analysis and many significant associations were identified (Tables 4). For example, high HER2 expression, as expected, was significantly correlated with the HER2+/ER- subtype and high ER expression was associated with both luminal subtypes (data not shown). EGFR expression was correlated with the basal-like subtype, while high HER4, AREG, and PIK3R1 expression was associated with the luminal A subtype. Many other associations with the basal-like subtype were also evident that included the high expression of Clusters \#1-3, TGFA, AKT3, CRYAB, MEK1, NRAS, KRAS gene and the KRAS-amplicon signature (Table 4). Other potentially biologically relevant associations included the high expression of Clusters \#2 and \#3, HRAS, MEK1, and $A K T 1$ with the HER2+/ER- subtype, and high expression of Clusters \#1-3 and HRAS with the luminal B subtype. Even though Clusters \#1-3 were identified using a basallike tumor derived cell line, associations with luminal and HER2+/ER- tumors were identified.
We also tested for associations between the high expression of Clusters \#1-3 with the high expression (i.e. top 1/ 3 highest group) of each of the above-mentioned genes in both the UNC and NKI datasets (Table 5). In both datasets, the high expression of MEK2 and HRAS was associated with Cluster \#1, while the high expression of many other genes correlated with Clusters 2 and 3; of note was the high expression of the KRAS-amplicon, HRAS, NRAS, and MEK1 with both Clusters \#2 and \#3, and the high expression of EGFR with only Cluster \#2. The association of different genes with the three EGFR-associated signatures is likely reflective of the complexity of signaling in this pathway across breast cancers and suggests possible driving molecular mechanisms for each EGFR-associated profile.

Lastly, a previously described mechanism for activation of the EGFR-RAS-MEK pathway is the somatic mutation of a $R A S$ gene, $B R A F$, or EGFR, which can be relatively frequent events in non-small cell lung carcinomas. We performed sequencing analyses on a subset of the UNC breast tumors analyzed by microarray for EGFR mutations in exons 19 
and 20, and for the common mutations in HRAS, KRAS and BRAF. No somatic sequence variants were detected in the 96 tumors that were analyzed, which were over sampled for basal-like and HER2+/ER- tumors.

\section{Discussion}

The epidermal growth factor receptor family is of tremendous biological and clinical importance for many solid epithelial tumors. In breast cancer patients, the response rate to single agent EGFR inhibitors has been low, however, these trials were performed on unselected patient populations [36,37] and response rates might be improved within biologically selected tumor subsets. The EGFR-pathway has become a potential target in the basallike subtype because at least $50 \%$ of basal-like tumors express EGFR as assessed by IHC [6]. Our in vitro analyses show that all basal-like cell lines tested were more sensitive to gefitinib compared to luminal cell lines. Only a single cell line (SUM102) was sensitive to cetuximab when EGF was present in the media, which is the condition that best mimics the in vivo environment [38].

Given the importance of combination therapies, we evaluated the combination of cetuximab and various chemotherapeutics in SUM102 cells and observed that the combination of cetuximab and carboplatin was highly synergistic at low doses of each drug. Even though the short-term co-treatment of cetuximab and carboplatin was antagonistic, synergism was observed in the longterm co-treatment. Carboplatin, as well as other platinum derivatives, may also be good chemotherapeutic agents for basal-like breast cancers due to the implicated function of the BRCA1-pathway in this subtype because BRCA1 mutation carriers are likely to develop tumors of the basal-like phenotype $[3,39,40]$. In our basal-like tumor-derived cell lines, it has been reported that the SUM149 line has a BRCA1 mutation and SUM102 line has barely detectable transcript levels of BRCA1 [41]. From a mechanistic standpoint, BRCA1 is required for repair of cisplatin induced DNA damage by recruiting RAD51 to the site of damage $[42,43]$ and BRCA1-deficient cells exhibit increased sensitivity to cisplatin compared to wild type cells [44-47]. The combination of an EGFR inhibitor and a platinum drug has also been found to be synergistic in several other cell types $[14,48,49]$. In our experiments, we showed that not only are the basal-like tumor derived cell lines the most sensitive to carboplatin and the EGFR inhibitors when applied individually, but also that the combination was synergistic. These results provide supportive preclinical evidence for an ongoing clinical trial for "triple-negative/basal-like" (i.e. ER-negative, PR-negative, and HER2-nonamplified) metastatic breast cancer patients who are receiving either cetuximab alone versus cetuximab plus carboplatin [50].
Given the biological importance of the EGFR pathway in epithelial tumors, we identified an EGFR-associated profile in vitro and examined its interplay with other biological features in vivo. In primary breast tumors, the SUM102defined set of EGFR-associated genes was broken into three distinct expression patterns (Figure 3 ), of which the high expression of two predicted poor patient outcomes in both the training and test data sets (i.e. Clusters \#2 and \#3). The prognostic ability of these clusters was further analyzed in the test set and Cluster \#2 could predict poor outcomes even after controlling for the standard clinical parameters in a Cox multivariate analysis. Of the three signatures, Cluster \#2 was the only cluster significantly associated with high EGFR gene expression.

Since most of the EGFR-associated in vivo profile genes did not have obvious functions in the HER family pathway (aside from Cyclin E1 in Cluster \#2), we searched for correlations with the expression levels of well known genes in the pathway. Many relationships were identified that could have important mechanistic implications (Tables 4 and 5). To assist in the interpretation of these complex patterns, we used the program Cytoscape $[51,52]$ to display the gene expression data in a pathway styled format and highlighted the statistically significant associations observed within each subtype (Figure 5). Each subtype had a distinct EGFR-pathway cartoon relative to both the EGFR-associated profiles, as well as the expression of key genes from the EGFR-RAS-MEK pathway. The luminal A subtype showed low expression of most of the genes we examined in the HER family pathway, and on average, was low for all three EGFR-associated profiles. One of the few genes whose high expression was significantly correlated with this subtype was the HER4 receptor (Figure 5A); high expression of HER4 and average expression of two of its ligands (HB-EGF and NRG1) was observed in this tumor subtype that typically shows low grade, slow growth, and an ER-rich expression signature.

The luminal B tumors showed moderate to high expression of the EGFR-associated profiles, high HRAS expression, and potentially high MEK2 expression (Figure 5B). The EGFR-HER2 pathway has often been implicated as a potential mechanism for tamoxifen resistance in ER+ patients [36,53-57]. We determined that the high expression of the EGFR-associated profiles was able to predict outcome differences in ER+ and tamoxifen-treated patients in both the UNC and NKI data sets (data not shown); however, it should be noted that the expression of these clusters in ER+ patients closely parallels the distinction of luminal A versus luminal B. These results suggest that part of the luminal A versus luminal B distinction is due to the activation of the EGFR/HER2 pathway in luminal B tumors. In support of this hypothesis, ninetysix percent of the luminal $\mathrm{B}$ tumors showed high expres- 
Table 5: Associations between Clusters \#I-3 and individual genes using the NKI295 sample set

\begin{tabular}{|c|c|c|c|c|c|c|}
\hline & \multicolumn{2}{|c|}{ Cluster I } & \multicolumn{2}{|c|}{ Cluster 2} & \multicolumn{2}{|c|}{ Cluster 3} \\
\hline & $\%$ & P-val & $\%$ & P-val & $\%$ & P-val \\
\hline EGFR & $39 \%$ & 0.1783 & $43 \%$ & $0.009 /^{b}$ & $38 \%$ & 0.15 \\
\hline HER2 & $26 \%$ & 0.0017 & $25 \%$ & $<0.000 l^{c} \mathrm{c}$ & $24 \%$ & $<\left.0.000\right|^{a}$ \\
\hline HER4* & $21 \%$ & $<0.0001$ & $12 \%$ & $<0.0001$ & $18 \%$ & $<0.0001$ \\
\hline TGFA & $40 \%$ & 0.0665 & $48 \%$ & 0.0002 & $47 \%$ & 0.0021 \\
\hline AREG & $22 \%$ & $0.0007^{c}$ & $23 \%$ & $<0.000 \mathrm{la}^{\mathrm{a}}$ & $28 \%$ & $0.064^{f}$ \\
\hline EGF & $35 \%$ & 0.1380 & $25 \%$ & 0.0691 & $27 \%$ & $0.033^{d}$ \\
\hline CRYAB & $35 \%$ & $0.3214^{f}$ & $38 \%$ & 0.0524 & $38 \%$ & 0.0013 \\
\hline KRAS amplicon & $38 \%$ & $0.1973^{e}$ & $52 \%$ & $<0.000 \mathrm{I}^{\mathrm{c}}$ & $63 \%$ & $<\left.0.000\right|^{a}$ \\
\hline KRAS gene & $27 \%$ & $0.0022^{a}$ & $31 \%$ & 0.8795 & $36 \%$ & $0.14 \mathrm{e}$ \\
\hline HRAS & $48 \%$ & $<0.0001 \mathrm{c}$ & $51 \%$ & $<0.0001$ & $47 \%$ & 0.0018 \\
\hline NRAS & $45 \%$ & 0.0362 & $56 \%$ & $<0.0001 \mathrm{c}$ & $59 \%$ & $<\left.0.000\right|^{a}$ \\
\hline PIK3ca & $22 \%$ & $0.0032^{b}$ & $27 \%$ & $0.1415^{\mathrm{e}}$ & $30 \%$ & $0.33^{e}$ \\
\hline PIK3RI & $24 \%$ & $0.0009^{a}$ & $20 \%$ & $<0.000 \mathrm{I}^{\mathrm{a}}$ & $19 \%$ & $<0.0001$ \\
\hline AKTI & $41 \%$ & 0.0112 & $39 \%$ & 0.0899 & $34 \%$ & 0.36 \\
\hline АKT2* & $40 \%$ & 0.0519 & $37 \%$ & 0.3524 & $33 \%$ & 0.94 \\
\hline AKT3 & $26 \%$ & 0.0004 & $33 \%$ & 0.1569 & $35 \%$ & $0.64^{f}$ \\
\hline MEKI & $39 \%$ & 0.0335 & $47 \%$ & $0.0032^{d}$ & $48 \%$ & $<0.0001$ \\
\hline MEK2 & $58 \%$ & $<0.000 \mathrm{la}^{\mathrm{a}}$ & $44 \%$ & $0.0113^{d}$ & $36 \%$ & $0.55^{f}$ \\
\hline ERKI & $37 \%$ & $0.0718 \mathrm{e}$ & $23 \%$ & $0.0009 c$ & $19 \%$ & $<\left.0.000\right|^{a}$ \\
\hline ERK2 & $39 \%$ & 0.0238 & $37 \%$ & $0.3457 e$ & $36 \%$ & $0.46^{e}$ \\
\hline
\end{tabular}

Chi-squared analyses were used to identify associations between the high expression of the individual EGFR-activation profiles for each cluster (top $\mathrm{I} / 3$ ) and the expression of individual genes categorized as high (top I/3). The \% of tumors with the high expression of each cluster and that show the high expression of the individual gene is shown.

*Note: HER4 could not be assessed in UNC data due to too many missing values; HER3 was not present in the NKI data set; AKT2 was not present in the UNC dataset.

a the statistically significant association was also significant in the UNC data set $(p<0.0025)$.

$b$ the association was nominally significant in the NKI dataset $(p<0.05)$, but significant in the UNC dataset ( $<<0.0025)$.

$c$ the association was significant in the NKI dataset $(p<0.0025)$, but nominally significant in the UNC dataset $(p<0.05)$.

$d$ the association was nominally significant in both datasets $(p<0.05)$.

e the association was significant in UNC dataset $(p<0.0025)$.

$f$ the association was nominally significant in the UNC dataset $(p<0.05)$.

Bonferroni corrected level of significance $\alpha=0.0025$

sion of at least one of the three EGFR-associated clusters, whereas only $24 \%$ of luminal A tumors had high expression of at least one. Our results are also consistent with the hypothesis of the "non-genomic" effects of ER to activate the HER pathway, where membrane bound ER complexes with EGFR and/or HER2 to cause activation of the RASMEK and p38 pathways $[53,54,58]$, and suggests that these ER "non-genomic" effects are occurring in luminal B tumors. Response to EGFR inhibitors in ER-positive tumors have been mixed with some indicating a benefit $[59,60]$, while others found no benefit [57]. A hypothesis that could be tested is that the high expression of one or more of the EGFR-associated gene sets in ER+ tumors might correlate with response/benefit to EGFR inhibitors.

The HER2+/ER- tumors, as expected, showed statistically high expression of HER2 and were also associated with high HRAS and MEK1/MEK2 (Figure 5C). High AKT1 levels were also associated with this tumor subtype, which has been previously identified [61,62].
The basal-like subtype showed the high expression of each of the three EGFR-associated profiles; ninety-one percent of the basal-like tumors had high expression of at least one of the signatures with $58 \%$ of the tumors having high expression of all three. High expression of many of the genes in the EGFR-RAS-MEK pathway were also significantly correlated with the basal-like subtype including EGFR, TGF $\alpha, M E K 1, M E K 2, A K T 3, C R Y A B, N R A S$ and the KRAS-amplicon signature (Figure 5D). For many of the genes or clusters examined here, as many as $70 \%$ of the basal tumors were in the highest $1 / 3$ expression group when compared to all other tumors. These data, when coupled to the EGFR inhibitor studies on breast cells lines, strongly suggest that the EGFR-RAS-MEK pathway plays an important role in the basal-like subtype's biology, and may be a requisite activating event for tumor formation.

The pathway analysis of the basal-like subtype has also potentially provided important mechanistic clues about how the EGFR-RAS-MEK pathway is activated in basal-like 

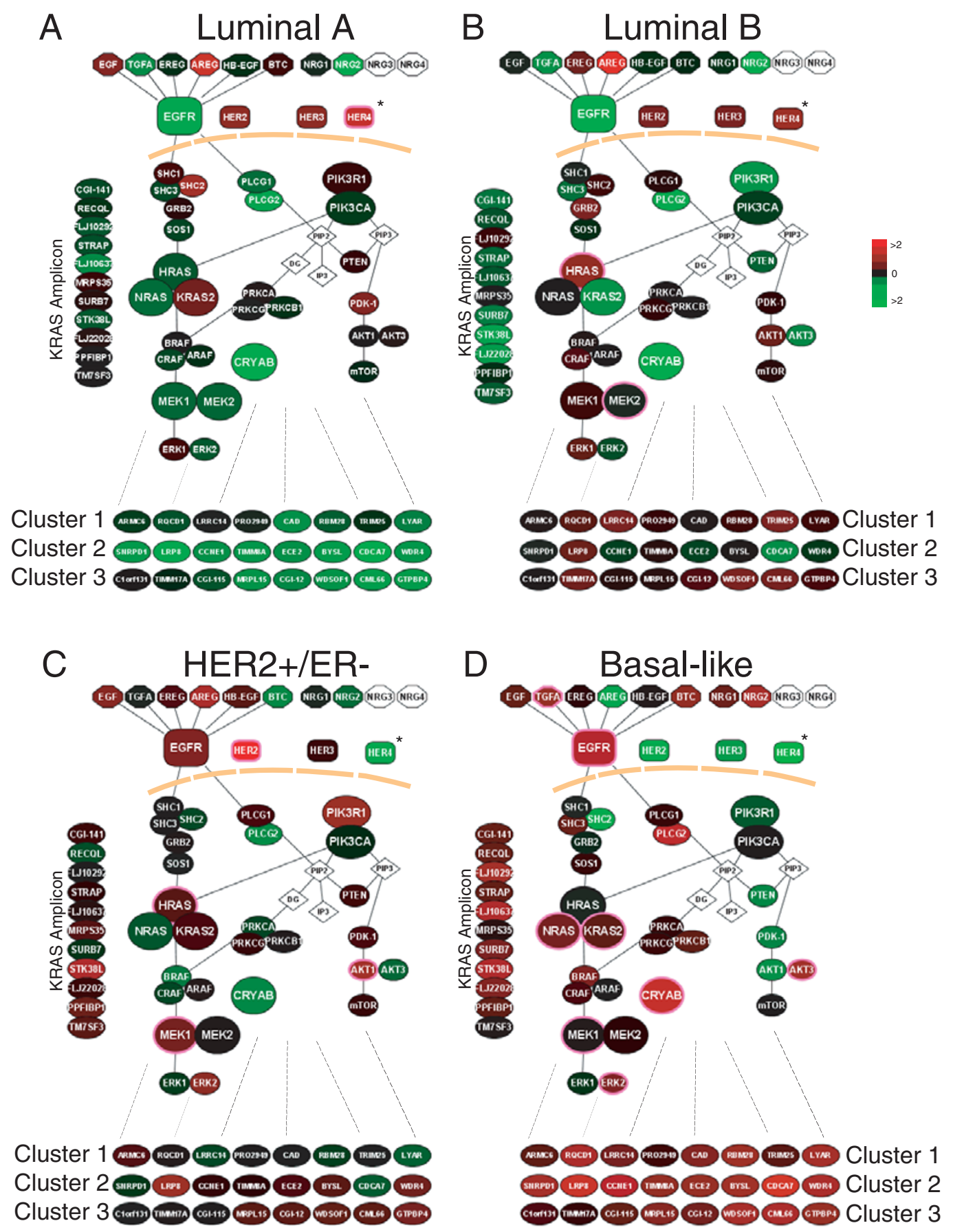

Figure 5

EGFR pathway diagram displayed for each breast tumor subtype. The average gene expression value for each gene within each subtype is displayed for the EGFR-pathway and for the three EGFR-activation profiles using the UNC 248 tumor dataset. Eight genes from the middle of each of the three EGFR-activation clusters were used to view expression of the clusters in each of the subtypes. A pink node border identifies the genes that showed statistically significant associations with subtype. *Note: the NKI HER4 data spot was used since HER4 was not present in the UNC data set. A) Luminal A, B) Luminal B, C) HER2+/ER- and D) Basal-like. 
tumors. One example concerns CRYAB, which has previously been shown to be highly expressed in many basallike tumors and to portend a poor outcome. Moyano et al. showed that the ectopic expression of CRYAB in breast epithelial cells caused them to become transformed and EGF-independent through activation of MEK [21]. This transformed phenotype was reverted by the addition of the MEK inhibitors PD98059 and U0126, while the PIK3 inhibitor LY294002 had little effect. CRYAB could also potentially confer resistance to EGFR inhibitors as well as chemotherapy by its anti-apoptotic mechanism, which is via the inhibition of caspase-3 activation [63,64]. Other potential activation events include the high expression of HRAS and KRAS; in particular, the KRAS-amplicon signature (which has also been identified in a murine model of basal-like tumors[35,65]), was highly expressed in $70 \%$ of the basal-like tumors and was shown to correlate with high expression of Cluster \#2. Given that most basal-like tumors showed either high expression of CRYAB or the KRAS-amplicon signature (greater than 85\%), drug targeting of the EGFR-RAS-MEK pathway downstream of EGFR (i.e. MEK inhibitors) might offer a more effective therapy than targeting of EGFR directly.

While these experiments only address gene expression patterns and not the protein levels or phosphorylation status of EGFR or RAS or MEK, we believe it is likely that these signatures are bona fide EGFR-pathway activation signatures. The supportive data for this hypothesis includes the in vitro observations that these are genes induced when an EGFR-dependent cell line is freed from growth inhibition via EGFR inhibitors and the in vivo associations between the high expression of these signatures and genes including HRAS, KRAS and EGFR itself. Regardless of the classical markers of activation of the EGFR-RAS-MEK pathway, the strong associations between these expression profiles and patient outcomes in two different data sets suggest that they are important profiles. Currently, we have chosen only to validate our profiles using additional microarray data sets, as opposed to using western blots or quantitative PCR of the training set, since each of these signatures represents a large number of genes/proteins. Many of these genes have no current link to the EGFR-signaling pathway and we cannot be sure of which genes are driving the prognostic significance of the clusters. If these signatures show additional promise for clinical application, detailed follow up will dissect which genes are important for prognosis, and then they will be confirmed using other platforms. Perhaps another utility of these profiles might be the ability to predict response to EGFR inhibitors, however, we could not test this hypothesis, as there are currently no large epithelial tumor EGFR inhibitor treated microarray data sets available. However, we believe that these signatures could represent a dynamic descriptor of pathway activity compared to EGFR protein status alone, which does not predict responsiveness to EGFR inhibitors [66-68].

\section{Conclusion}

The EGFR pathway is a complex signaling network and differences in gene expression levels of its various components can be observed across the breast cancer subtypes. EGFR-associated gene expression profiles derived in vitro were prognostic in two independent breast tumor data sets. Using these EGFR-associated gene expression profiles, and gene expression levels of known genes within the EGFR pathway, we have identified key differences in this pathway across the subtypes. A better understanding of each subtype's EGFR signaling pathway will have an impact on identifying and determining treatment as the gene expression signature may more readily be associated with activation of the pathway than EGFR status alone.

\section{Methods \\ Cell culture}

SUM102 and SUM149 cells were a gift from Steve Ethier of Wayne State University [69] and represent cell lines derived from ER- and HER2- basal-like breast tumors. The SUM cell lines were maintained in an Epithelial Growth Medium developed by the Tissue Culture Facility at the University of North Carolina at Chapel Hill [70], and the SUM149 line was further supplemented with 5\% FBS. The MCF-7, ZR-75-1, HME-CC and ME16C cell lines were obtained and maintained as previously described [22,23].

\section{Cytotoxicity assay}

Cell line sensitivities to drugs were assessed using a mitochondrial dye conversion assay (MTT, Cell Titer 96, Promega, Madison, WI) as described previously with the following modifications [22]. Cells were seeded into triplicate 96-well plates (SUM102, HME-CC, and ME16C 5,000 cells/well, SUM149 - 10,000 cells/well, MCF-7 and ZR-75-1 - 7,000 cells/well) and allowed to adhere overnight. Cells were treated for $72 \mathrm{~h}$ with a range of doses of individual drugs. Carboplatin, doxorubicin, 5-fluorouracil, paclitaxel, and LY294002 were purchased from Sigma (St. Louis, MO). Gefitinib was a gift from AstraZeneca and cetuximab was purchased from the UNC Hospitals Pharmacy Storeroom (Chapel Hill, NC). U0126 was purchased from Cell Signaling (Danvers, MA). The inhibitory concentration that caused a 50\% reduction in MTT dye conversion (IC50) dose was determined as previously described [22].

Drug combination interactions were analyzed using methods developed by Chou and Talalay [26]. Using cell lines plated as described above, seven treatment combinations consisting of constant ratios of IC50 doses (ranging from one-eighth of each dose to eight times the IC50) were applied to cells and growth compared to untreated 
controls using the MTT assay. Four treatment schedules were tested: $72 \mathrm{~h}$ concurrent, $72 \mathrm{~h}$ inhibitor followed by $72 \mathrm{~h}$ chemotherapeutic, $72 \mathrm{~h}$ chemotherapeutic followed by $72 \mathrm{~h}$ inhibitor, and a $144 \mathrm{~h}$ concurrent dose with a media change at $72 \mathrm{~h}$ (similar to the sequential treatments). CalcuSyn (BioSoft, Cambridge, UK) was used to determine the combination index, which is a measurement of the type of drug interactions. A combination index (CI) of one indicates an additive response, less than one indicates a synergistic response (greater than additive), and greater than one indicates an antagonistic response (less than additive).

\section{Collection of mRNA for cell line experiments}

For each treatment, the SUM102 cells were grown in 15$\mathrm{cm}$ dishes until 50-60\% confluence. SUM102 cells were treated for $48 \mathrm{~h}$ with a dose equivalent to two times the 72h-IC50 dose of each inhibitor (treated samples). To identify EGFR, MEK, and PI3K activation signatures, the medium was removed after $48 \mathrm{~h}$ of inhibitor treatment and replaced with fresh medium without inhibitor. mRNA was harvested at $4 \mathrm{~h}, 8 \mathrm{~h}$, and $24 \mathrm{~h}$ (post treatment samples). Cells were harvested by scraping, quickly placed into RNA lysis buffer, and mRNA was isolated using the Micro-FastTrack kit (Invitrogen, Carlsbad, CA).

\section{Collection of RNA for human tumor samples}

248 breast tissue samples represented by 241 fresh frozen breast tumor samples and 7 normal breast tissue samples were obtained from four different sources using IRB approved protocols from each participating institution: the University of North Carolina at Chapel Hill, The University of Utah, Thomas Jefferson University and the University of Chicago; many of these samples have appeared in previous publications [71-74], and 117 are new to this study (see Additional file 5). The patients were heterogeneously treated in accordance with the standard of care dictated by their disease stage, ER, and HER2 status.

\section{Tumor sequence analysis}

Tumor genomic DNA samples were isolated from 96 tumors using Qiagen (Valencia, CA) DNeasy Kits according to the manufacturers protocol. Gene sequencing analyses were performed at Polymorphic DNA Technologies (Alameda, CA) using an ABI 3730xl DNA sequencer and cycle sequencing, according to the manufacturers protocol. A two-step "boost/nested" PCR strategy was used where first a PCR reaction is performed to generate a larger DNA fragment, which is then used as a template for the nested reaction with a second set of PCR primers. Double stranded sequencing was performed on the nested product using the nested PCR primers as the sequencing primers. Exons 19 and 21 of EGFR were sequenced across all 96 patients, while exons 1 and 2 of KRAS2, 1 and 2 of HRAS, and 11 and 15 of BRAF were sequenced across 54 patients. No somatic alterations were detected.

\section{Microarray experiments}

For the human tumor samples, the total RNA isolation and microarray protocols were performed as described in Hu et al. [5]; in this study, a number of tumor samples from previous studies were retested using a new custom Agilent microarray enriched for breast cancer genes. For cell lines experiments, labeled cRNA was generated from the mRNA using Agilent's Low RNA Input Linear Amplification Kit as described in $\mathrm{Hu}$ et al. [5]. For the cell line studies, the $48 \mathrm{~h}$ inhibitor treated samples were compared to an untreated cell line reference to look for effects of an inhibitor, and for the post treatment samples, to identify an activation signature for that drug/pathway. Labeled experimental sample (Cy5 CTP) and reference (Сy3 CTP) were mixed and co-hybridized overnight on the same Custom 22K Agilent Human Whole Genome Oligonucleotide Microarray described above. Two to four microarrays per experimental cell line condition were performed, including a dye-flip replicate for gefitinib- and cetuximabtreated samples. Microarrays were scanned on an Axon GenePix 4000B microarray scanner and analyzed using GenePix Pro 5.1 software. Microarray raw data were uploaded into the UNC Microarray Database and Lowess normalization was performed on the Cy3 and Cy5 channels. The microarray and patient clinical data are available at UNC Microarray Database [75] and have been deposited in the Gene Expression Omnibus under the accession number GSE6128.

\section{Statistical analyses}

Intra-class correlations between cell line microarray experiments were performed to judge the degree of concordance between experiments/samples as described in $\mathrm{Hu}$ et al. [5]. Unsupervised analyses of the cell line samples were performed by selecting genes with an absolute signal intensity of at least 30 units (our cutoff for background signal intensity) in both channels in at least $70 \%$ of the samples tested and that also showed a $\log _{2} R / G$ Lowess normalized ratio of two on at least two arrays. The program Cluster was used to hierarchically cluster samples and genes, and Treeview was used to view the data $[76,77]$. Using the SUM102 treated cells, a one-class Significance Analysis of Microarrays (SAM) was used to identify significantly induced genes in all the post treatment experiments (two to three arrays for each experimental time point) [78]. Gene ontology enrichment was assessed using EASE [79].

Analyses of the primary tumor data used the top 500 induced genes from the cell line SAM analysis described above, after filtering for 30 units in both channels in at least $70 \%$ of the tumor samples. These genes were exam- 
ined in a two-way hierarchical clustering analysis with the 248 UNC tumor sample set. Three distinct expression patterns were observed and labeled as Clusters \#1-3. Next, the genes in each of these three tumor-defined clusters were identified in the NKI295 patient data set $[33,34]$, and a mean expression value for each cluster for each patient was determined. The NKI295 patients were then rank-ordered and separated into (a) two equal groups representing low and high, or (b) three equal groups representing low, medium, and high average expression for each cluster. In addition, similar gene-based rank order patient stratifications were performed for individual genes that included EGFR, HER2, HER4, EGF, TGFA, AREG, CRYAB, KRAS, KRAS-amplicon profile, HRAS, NRAS, PIK3CA, PIK3R1, AKT1, AKT2, AKT3, MEK1, MEK2, $E R K 1$, and ERK2. Survival analyses were performed using Cox-Mantel log-rank test in Winstat for Excel (R. Fitch Software). Multivariate Cox proportional hazards analysis was performed in SAS v9.0 (SAS Statistical Software, Cary, $\mathrm{NC)}$ to estimate the hazard ratio associated with cluster expression in the three groups after controlling for standard clinical predictors (age, ER status, size, grade, and node status). Chi Square tests (SAS v9.0) were used to examine correlations between cluster groups, individual genes, and tumor subtype.

Gene expression relative levels were visualized in relation to the EGFR signaling pathway using Cytoscape [51,52]. The pathway was built de novo based on information from KEGG [80,81], BioCarta [82], and a review by Yarden and Silowkoski [1] with a focus on the RAS-MEK and PI3K/ AKT components. Using the 248 UNC breast tumor microarray dataset, an average gene expression profile is displayed for the Luminal A, Luminal B, basal-like, and HER2+/ER- tumors. Tumor "intrinsic" subtype was determined for each sample using the 306 gene Centroid Predictor described in $\mathrm{Hu}$ et al. [71]; the subtype classifications used for the NKI295 sample set were also derived from this same centroid predictor and are described in Fan et al. [83].

\section{Abbreviations}

EGFR/HER1: epidermal growth factor receptor; ER: estrogen receptor; HER: human epidermal growth factor receptor; MTT: mitochondrial dye conversion assay [3- $(4,5-$ dimethylthiazol-2-yl)-2,5-diphenyltetrazolium bromide]; CI: Combination Index; SAM: Significance Analysis of Microarrays; HMEC: human mammary epithelial cell; FDR: false discovery rate; GO: gene ontology; RFS: relapsefree survival; OS: overall survival; HR: hazard ratio; $95 \%$ CI: 95\% confidence interval; ICC: Intraclass correlation; PgR: progesterone receptor.

\section{Authors' contributions}

KAH performed the cell line experiments, cell line and tumor data analysis, drafted the paper and helped with the design of the study. VJW, CF, MAT assisted with data analysis. CIS made initial observations of EGFR dependency of SUM102 cells and assisted with the discussion. Tumor sample collection, clinical data acquisition and interpretations were accomplished by LAC, LRS, TRH, and PSB. XH performed tumor RNA preparation and microarray experiments for tumor samples. CMP was the Principal Investigator, instigated and designed the study, and helped draft the paper.

\section{Additional material}

\section{Additional file 1}

Gefitinib and carboplatin combinations in breast cancer-derived cell lines. Cells were treated for $72 \mathrm{~h}$ with constant ratios of the IC50 doses for both gefitinib and carboplatin. Combination Index (CI) values below one are synergistic, equal to one are additive, and greater than one are antagonistic.

Click here for file

[http://www.biomedcentral.com/content/supplementary/14712164-8-258-S1.pdf]

\section{Additional file 2}

Full cluster diagram for the gene expression patterns of SUM102 cells treated with gefitinib or cetuximab.

Click here for file

[http://www.biomedcentral.com/content/supplementary/1471-

2164-8-258-S2.pdf]

\section{Additional file 3}

Full cluster diagram for the in vivo EGFR-activation profiles clustered on the UNC tumor data set.

Click here for file

[http://www.biomedcentral.com/content/supplementary/14712164-8-258-S3.pdf]

\section{Additional file 4}

Genes from Cluster \#1-3. Genes identified from the 500 SUM102 genes clustered on the UNC tumor dataset.

Click here for file

[http://www.biomedcentral.com/content/supplementary/14712164-8-258-S4.doc]

\section{Additional file 5}

Clinical data associated with each tumor sample. Click here for file

[http://www.biomedcentral.com/content/supplementary/14712164-8-258-S5.xls]

\section{Acknowledgements}

We thank AstraZeneca for the gift of gefitinib. We thank Steve Ethier for the gift of SUMIO2 and SUMI 49 cell lines. This work was supported by funds for CMP from the NCI Breast SPORE program to UNC-CH (P50CA58223-09AI), by ROI-CA-I0I227-0I, and by the $V$ Foundation for Cancer Research. LAC was supported by MOIRR00046, and K.H. was sup- 
ported by a Department of Defense Breast Cancer Program Predoctoral Fellowship W8IXWH-05-I-0288.

\section{References}

I. Yarden Y, Sliwkowski MX: Untangling the ErbB signalling network. Nat Rev Mol Cell Biol 200I, 2:127-I37.

2. Sørlie T, Perou CM, Tibshirani R, Aas T, Geisler S, Johnsen H, Hastie $T$, Eisen MB, van de Rijn M, Jeffrey SS, Thorsen T, Quist $H$, Matese JC, Brown PO, Botstein D, Eystein Lonning P, Borresen-Dale AL: Gene expression patterns of breast carcinomas distinguish tumor subclasses with clinical implications. Proc Natl Acad Sci U S A 200I, 98: I0869-I0874.

3. Sørlie T, Tibshirani R, Parker J, Hastie T, Marron JS, Nobel A, Deng S Johnsen H, Pesich R, Geisler S, Demeter J, Perou CM, Lonning PE, Brown PO, Borresen-Dale AL, Botstein D: Repeated observation of breast tumor subtypes in independent gene expression data sets. Proc Natl Acad Sci U S A 2003, 100:8418-8423.

4. Perou CM, Sørlie T, Eisen MB, van de Rijn M, Jeffrey SS, Rees CA, Pollack JR, Ross DT, Johnsen H, Akslen LA, Fluge O, Pergamenschikov A Williams C, Zhu SX, Lonning PE, Borresen-Dale AL, Brown PO, Botstein D: Molecular portraits of human breast tumours. Nature 2000, 406:747-752.

5. Hu Z, Troester M, Perou CM: High reproducibility using sodium hydroxide-stripped long oligonucleotide DNA microarrays. Biotechniques 2005, 38: 121-124.

6. Nielsen TO, Hsu FD, Jensen K, Cheang M, Karaca G, Hu Z, Hernandez-Boussard T, Livasy C, Cowan D, Dressler L, Akslen LA, Ragaz J, Gown AM, Gilks CB, van De Rijn M, Perou CM: Immunohistochemical and clinical characterization of the basal-like subtype of invasive breast carcinoma. Clin Cancer Res 2004 10:5367-3574

7. Salomon DS, Brandt R, Ciardiello F, Normanno N: Epidermal growth factor-related peptides and their receptors in human malignancies. Crit Rev Oncol Hematol 1995, 19:183-232.

8. Mass RD: The HER receptor family: a rich target for therapeutic development. Int J Radiat Oncol Biol Phys 2004, 58:932-940.

9. Baselga J: Why the epidermal growth factor receptor? The rationale for cancer therapy. Oncologist 2002, 7 Suppl 4:2-8.

10. Culy CR, Faulds D: Gefitinib. Drugs 2002, 62:2237-48; discussion 2249-50.

II. Graham J, Muhsin M, Kirkpatrick P: Cetuximab. Nat Rev Drug Discov 2004, 3:549-550.

12. Dowell J, Minna JD, Kirkpatrick P: Erlotinib hydrochloride. Nat Rev Drug Discov 2005, 4: I3-14.

13. Tamura K, Fukuoka M: Molecular target-based cancer therapy: tyrosine kinase inhibitors. Int / Clin Oncol 2003, 8:207-2 I I.

14. Ciardiello F, Caputo R, Bianco R, Damiano V, Pomatico G, De Placido $S$, Bianco AR, Tortora G: Antitumor effect and potentiation of cytotoxic drugs activity in human cancer cells by ZD- I839 (Iressa), an epidermal growth factor receptor-selective tyrosine kinase inhibitor. Clin Cancer Res 2000, 6:2053-2063.

15. She QB, Solit D, Basso A, Moasser MM: Resistance to gefitinib in PTEN-null HER-overexpressing tumor cells can be overcome through restoration of PTEN function or pharmacologic modulation of constitutive phosphatidylinositol 3'kinase/Akt pathway signaling. Clin Cancer Res 2003, 9:4340-4346.

16. Moasser MM, Basso A, Averbuch SD, Rosen N: The tyrosine kinase inhibitor ZDI 839 ("Iressa") inhibits HER2-driven signaling and suppresses the growth of HER2-overexpressing tumor cells. Cancer Res 200I, 6I:7I84-7I88.

17. Bianco R, Shin I, Ritter CA, Yakes FM, Basso A, Rosen N, Tsurutani J, Dennis PA, Mills GB, Arteaga CL: Loss of PTEN/MMACI/TEP in EGF receptor-expressing tumor cells counteracts the antitumor action of EGFR tyrosine kinase inhibitors. Oncogene 2003 , 22:2812-2822.

18. Lev DC, Kim LS, Melnikova V, Ruiz M, Ananthaswamy HN, Price JE: Dual blockade of EGFR and ERKI/2 phosphorylation potentiates growth inhibition of breast cancer cells. Br J Cancer 2004 91:795-802.

19. Normanno N, De Luca A, Maiello MR, Campiglio M, Napolitano M, Mancino M, Carotenuto A, Viglietto G, Menard S: The MEK/MAPK pathway is involved in the resistance of breast cancer cells to the EGFR tyrosine kinase inhibitor gefitinib. J Cell Physiol 2006 , 207:420-427.
20. Janmaat ML, Rodriguez JA, Gallegos-Ruiz M, Kruyt FA, Giaccone G: Enhanced cytotoxicity induced by gefitinib and specific inhibitors of the Ras or phosphatidyl inositol-3 kinase pathways in non-small cell lung cancer cells. Int / Cancer 2006, I | 8:209-2| 4

21. Moyano JV, Evans JR, Chen F, Lu M, Werner ME, Yehiely F, Diaz LK, Turbin D, Karaca G, Wiley E, Nielsen TO, Perou CM, Cryns VL: AlphaB-crystallin is a novel oncoprotein that predicts poor clinical outcome in breast cancer. J Clin Invest 2006, I | 6:26I-270.

22. Troester MA, Hoadley KA, Sorlie T, Herbert BS, Borresen-Dale AL, Lonning PE, Shay JW, Kaufmann WK, Perou CM: Cell-Type-Specific Responses to Chemotherapeutics in Breast Cancer. Cancer Res 2004, 64:4218-4226.

23. Troester MA, Hoadley KA, Parker JS, Perou CM: Prediction of toxicant-specific gene expression signatures after chemotherapeutic treatment of breast cell lines. Environ Health Perspect 2004, I I 2:1607-1613

24. Sartor Cl, Dziubinski ML, Yu CL, Jove R, Ethier SP: Role of epidermal growth factor receptor and STAT-3 activation in autonomous proliferation of SUM-I02PT human breast cancer cells. Cancer Res 1997, 57:978-987.

25. Bertucci F, Finetti P, Rougemont J, Charafe-Jauffret E, Cervera N, Tarpin C, Nguyen C, Xerri L, Houlgatte R, Jacquemier J, Viens P, Birnbaum D: Gene expression profiling identifies molecular subtypes of inflammatory breast cancer. Cancer Res 2005, 65:2170-2178.

26. Chou TC, Talalay P: Quantitative analysis of dose-effect relationships: the combined effects of multiple drugs or enzyme inhibitors. Adv Enzyme Regul 1984, 22:27-55

27. Schraml P, Bucher C, Bissig H, Nocito A, Haas P, Wilber K, Seelig S, Kononen J, Mihatsch MJ, Dirnhofer S, Sauter G: Cyclin E overexpression and amplification in human tumours. J Pathol 2003, 200:375-382.

28. Sieuwerts AM, Look MP, Meijer-van Gelder ME, Timmermans $M$ Trapman AM, Garcia RR, Arnold M, Goedheer AJ, de Weerd V, Portengen H, Klijn JG, Foekens JA: Which cyclin E prevails as prognostic marker for breast cancer? Results from a retrospective study involving 635 lymph node-negative breast cancer patients. Clin Cancer Res 2006, I 2:3319-3328.

29. Foulkes WD, Brunet JS, Stefansson IM, Straume O, Chappuis PO, Begin LR, Hamel N, Goffin JR, Wong N, Trudel M, Kapusta L, Porter $P$, Akslen LA: The prognostic implication of the basal-like (cyclin E high/p27 low/p53+/glomeruloid-microvascular-proliferation+) phenotype of BRCAI-related breast cancer. Cancer Res 2004, 64:830-835.

30. Navolanic PM, Steelman LS, McCubrey JA: EGFR family signaling and its association with breast cancer development and resistance to chemotherapy (Review). Int I Oncol 2003, 22:237-252.

31. Medema RH, Kops GJ, Bos JL, Burgering BM: AFX-like Forkhead transcription factors mediate cell-cycle regulation by Ras and PKB through p27kip I. Nature 2000, 404:782-787.

32. Delmas C, Manenti S, Boudjelal A, Peyssonnaux C, Eychene A, Darbon JM: The p42/p44 mitogen-activated protein kinase activation triggers p27Kip I degradation independently of CDK2/ cyclin E in NIH 3T3 cells. I Biol Chem 200I, 276:34958-34965.

33. van de Vijver MJ, He YD, van't Veer LJ, Dai H, Hart AA, Voskuil DW, Schreiber G], Peterse JL, Roberts C, Marton MJ, Parrish M, Atsma D, Witteveen A, Glas A, Delahaye $L$, van der Velde T, Bartelink $H$, Rodenhuis S, Rutgers ET, Friend SH, Bernards R: A gene-expression signature as a predictor of survival in breast cancer. $N$ Engl J Med 2002, 347:1999-2009.

34. Chang HY, Nuyten DS, Sneddon JB, Hastie T, Tibshirani R, Sorlie T, Dai $H$, He YD, van't Veer LJ, Bartelink $H$, van de Rijn M, Brown PO, van de Vijver MJ: Robustness, scalability, and integration of a wound-response gene expression signature in predicting breast cancer survival. Proc Natl Acad Sci U S A 2005, 102:3738-3743.

35. Herschkowitz JI, Simin K, Weigman VJ, Mikaelian I, Usary J, Hu Z, Rasmussen KE, Jones LP, Assefnia S, Chandrasekharan S, Backlund MG, Yin Y, Khramtsov AI, Bastein R, Quackenbush J, Glazer RI, Brown PH, Green JE, Kopelovich L, Furth PA, Palazzo JP, Olopade OI, Bernard PS, Churchill GA, Van Dyke T, Perou CM: Identification of conserved gene expression features between murine mammary carcinoma models and human breast tumors. Genome Bio 2007, 8:R76. 
36. Normanno N, De Luca A, Maiello MR, Mancino M, D'Antonio A Macaluso M, Caponigro F, Giordano A: Epidermal growth factor receptor (EGFR) tyrosine kinase inhibitors in breast cancer: current status and future development. Front Biosci 2005, 10:2611-2617

37. Agrawal A, Gutteridge E, Gee JM, Nicholson RI, Robertson JF: Overview of tyrosine kinase inhibitors in clinical breast cancer. Endocr Relat Cancer 2005, I 2 Suppl I:SI35-44.

38. Singh $A B$, Harris $R C$ : Autocrine, paracrine and juxtacrine signaling by EGFR ligands. Cell Signal 2005, I 7: I I83-I I 93.

39. Arnes JB, Brunet JS, Stefansson I, Begin LR, Wong N, Chappuis PO, Akslen LA, Foulkes WD: Placental cadherin and the basal epithelial phenotype of BRCAI-related breast cancer. Clin Cancer Res 2005, I I:4003-40 I I

40. Foulkes WD, Stefansson IM, Chappuis PO, Begin LR, Goffin JR, Wong N, Trudel M, Akslen LA: Germline BRCAI mutations and a basal epithelial phenotype in breast cancer. J Natl Cancer Inst 2003, 95: | 482-| 485

41. Elstrodt F, Hollestelle A, Nagel JH, Gorin M, Wasielewski M, van den Ouweland A, Merajver SD, Ethier SP, Schutte M: BRCAI mutation analysis of $4 \mathrm{I}$ human breast cancer cell lines reveals three new deleterious mutants. Cancer Res 2006, 66:4I-45.

42. Zhou C, Huang P, Liu J: The carboxyl-terminal of BRCAl is required for subnuclear assembly of RAD5 I after treatment with cisplatin but not ionizing radiation in human breast and ovarian cancer cells. Biochem Biophys Res Commun 2005 336:952-960.

43. Bhattacharyya A, Ear US, Koller BH, Weichselbaum RR, Bishop DK: The breast cancer susceptibility gene BRCAI is required for subnuclear assembly of Rad5I and survival following treatment with the DNA cross-linking agent cisplatin. J Biol Chem 2000, 275:23899-23903.

44. Husain A, He G, Venkatraman ES, Spriggs DR: BRCAI up-regulation is associated with repair-mediated resistance to cisdiamminedichloroplatinum(II). Cancer Res I998, 58: I I 20- I I 23.

45. Tassone P, Tagliaferri P, Perricelli A, Blotta S, Quaresima B, Martell ML, Goel A, Barbieri V, Costanzo F, Boland CR, Venuta S: BRCAI expression modulates chemosensitivity of BRCAI-defective HCCI937 human breast cancer cells. Br J Cancer 2003, 88: $|285-129|$

46. Quinn JE, Kennedy RD, Mullan PB, Gilmore PM, Carty M, Johnston PG, Harkin DP. BRCAI functions as a differential modulator of chemotherapy-induced apoptosis. Cancer Res 2003. 63:6221-6228.

47. Kennedy RD, Quinn JE, Mullan PB, Johnston PG, Harkin DP: The role of BRCAI in the cellular response to chemotherapy. J Nat Cancer Inst 2004, 96: 1659-1668.

48. Morelli MP, Cascone T, Troiani T, De Vita F, Orditura M, Laus G, Eckhardt SG, Pepe S, Tortora G, Ciardiello F: Sequence-dependent antiproliferative effects of cytotoxic drugs and epidermal growth factor receptor inhibitors. Ann Oncol 2005, 16 Suppl 4:iv6I-iv68.

49. Hambek M, Baghi M, Strebhardt K, Baumann H, Gstottner W, Knecht R: Reduction of cisplatin dosage by ZD 1839. Anticancer Res 2005, 25:3985-3988.

50. Cetuximab Alone and Cetuximab With Carboplatin in ER PR-Negative, HER-2 Nonoverexpressing Metastatic Breast Cancer [http://www.clinicaltrials.gov/ct/show/NCT00232505]

51. Cytoscape [http://www.cytoscape.org]

52. Shannon P, Markiel A, Ozier O, Baliga NS, Wang JT, Ramage D, Amin N, Schwikowski B, Ideker T: Cytoscape: A Software Environment for Integrated Models of Biomolecular Interaction Networks. Genome Res 2003, I 3:2498-2504.

53. Gutierrez MC, Detre S, Johnston S, Mohsin SK, Shou J, Allred DC, Schiff R, Osborne CK, Dowsett M: Molecular changes in tamoxifen-resistant breast cancer: relationship between estrogen receptor, HER-2, and p38 mitogen-activated protein kinase. J Clin Oncol 2005, 23:2469-2476.

54. Arpino G, Green S], Allred DC, Lew D, Martino S, Osborne CK Elledge RM: HER-2 amplification, HER-I expression, and tamoxifen response in estrogen receptor-positive metastatic breast cancer: a southwest oncology group study. Clin Cancer Res 2004, 10:5670-5676.

55. Britton DJ, Hutcheson IR, Knowlden JM, Barrow D, Giles M, McClelland RA, Gee JM, Nicholson RI: Bidirectional cross talk between
ERalpha and EGFR signalling pathways regulates tamoxifenresistant growth. Breast Cancer Res Treat 2006, 96: I3 I-146.

56. Ellis MJ, Tao Y, Young O, White S, Proia AD, Murray J, Renshaw L, Faratian D, Thomas J, Dowsett M, Krause A, Evans DB, Miller WR, Dixon JM: Estrogen-independent proliferation is present in estrogen-receptor HER2-positive primary breast cancer after neoadjuvant letrozole. I Clin Oncol 2006, 24:3019-3025.

57. Dowsett M, Houghton J, Iden C, Salter J, Farndon J, A'Hern R, Sainsbury $R$, Baum M: Benefit from adjuvant tamoxifen therapy in primary breast cancer patients according oestrogen receptor, progesterone receptor, EGF receptor and HER2 status. Ann Oncol 2006, I 7:818-826.

58. Shou J, Massarweh S, Osborne CK, Wakeling AE, Ali S, Weiss H, Schiff R: Mechanisms of tamoxifen resistance: increased estrogen receptor-HER2/neu cross-talk in ER/HER2-positive breast cancer. J Natl Cancer Inst 2004, 96:926-935.

59. Ciardiello F, Troiani T, Caputo F, De Laurentiis M, Tortora G, Palmieri G, De Vita F, Diadema MR, Orditura M, Colantuoni G, Gridelli C, Catalano G, De Placido S, Bianco AR: Phase II study of gefitinib in combination with docetaxel as first-line therapy in metastatic breast cancer. Br / Cancer 2006, 94: I604-I609.

60. Polychronis A, Sinnett HD, Hadjiminas D, Singhal H, Mansi JL, Shivapatham D, Shousha S, Jiang J, Peston D, Barrett N, Vigushin D, Morrison K, Beresford E, Ali S, Slade MJ, Coombes RC: Preoperative gefitinib versus gefitinib and anastrozole in postmenopausal patients with oestrogen-receptor positive and epidermalgrowth-factor-receptor-positive primary breast cancer: a double-blind placebo-controlled phase II randomised trial. Lancet Oncol 2005, 6:383-391.

61. Tokunaga E, Kimura Y, Oki E, Ueda N, Futatsugi M, Mashino K, Yamamoto $M$, Ikebe $M$, Kakeji $Y$, Baba $H$, Maehara $Y$ : Akt is frequently activated in HER2/neu-positive breast cancers and associated with poor prognosis among hormone-treated patients. Int J Cancer 2006, I I 8:284-289.

62. Zhou X, Tan M, Stone Hawthorne V, Klos KS, Lan KH, Yang Y, Yang W, Smith TL, Shi D, Yu D: Activation of the Akt/mammalian target of rapamycin/4E-BPI pathway by ErbB2 overexpression predicts tumor progression in breast cancers. Clin Cancer Res 2004, 10:6779-6788.

63. Kamradt MC, Chen F, Cryns VL: The small heat shock protein alpha B-crystallin negatively regulates cytochrome c- and caspase-8-dependent activation of caspase-3 by inhibiting its autoproteolytic maturation. J Biol Chem 200I, 276: I6059-I 6063

64. Kamradt MC, Lu M, Werner ME, Kwan T, Chen F, Strohecker A, Oshita S, Wilkinson JC, Yu C, Oliver PG, Duckett CS, Buchsbaum DJ, LoBuglio AF, Jordan VC, Cryns VL: The small heat shock protein alpha B-crystallin is a novel inhibitor of TRAIL-induced apoptosis that suppresses the activation of caspase-3. I Biol Chem 2005, 280: I 1059- I I066.

65. Liu ML, Shibata MA, Von Lintig FC, Wang W, Cassenaer S, Boss GR, Green JE: Haploid loss of Ki-ras delays mammary tumor progression in C3 (I)/SV40 Tag transgenic mice. Oncogene 200I, 20:2044-2049.

66. von Minckwitz G, Jonat W, Fasching P, du Bois A, Kleeberg U, Luck HJ, Kettner E, Hilfrich J, Eiermann W, Torode J, Schneeweiss A: A multicentre phase II study on gefitinib in taxane- and anthracycline-pretreated metastatic breast cancer. Breast Cancer Res Treat 2005, 89:165-172.

67. Gasparini G, Sarmiento R, Amici S, Longo R, Gattuso D, Zancan M, Gion M: Gefitinib (ZD I 839) combined with weekly epirubicin in patients with metastatic breast cancer: a phase I study with biological correlate. Ann Oncol 2005, 16:1867-1873.

68. Fountzilas G, Pectasides D, Kalogera-Fountzila A, Skarlos D, Kalofonos HP, Papadimitriou C, Bafaloukos D, Lambropoulos S, Papadopoulos S, Kourea H, Markopoulos C, Linardou H, Mavroudis D, Briasoulis E, Pavlidis N, Razis E, Kosmidis P, Gogas H: Paclitaxel and carboplatin as first-line chemotherapy combined with gefitinib (IRESSA) in patients with advanced breast cancer: a phase I/II study conducted by the Hellenic Cooperative Oncology Group. Breast Cancer Res Treat 2005, 92: I-9.

69. Asterand: Human breast cancer cell lines [http:www.asterand.com/AsteranBIOREPOSITORhbreastcancercell lines.aspx

70. Tissue Culture Facility at the University of North Carolina at Chapel Hill [http://www.unc.edu/depts/tcf/info.html] 
7I. Hu Z, Fan C, Oh DS, Marron JS, He X, Qaqish BF, Livasy C, Carey LA, Reynolds E, Dressler L, Nobel A, Parker J, Ewend MG, Sawyer LR, Wu J, Liu Y, Nanda R, Tretiakova M, Ruiz Orrico A, Dreher D, Palazzo JP, Perreard L, Nelson E, Mone M, Hansen H, Mullins M, Quackenbush JF, Ellis MJ, Olopade OI, Bernard PS, Perou CM: The molecular portraits of breast tumors are conserved across microarray platforms. BMC Genomics 2006, 7:96.

72. Oh DS, Troester MA, Usary J, Hu Z, He X, Fan C, Wu J, Carey LA, Perou CM: Estrogen-regulated genes predict survival in hormone receptor-positive breast cancers. J Clin Oncol 2006, 24:1656-1664.

73. Weigelt B, Hu Z, He X, Livasy C, Carey LA, Ewend MG, Glas AM, Perou CM, Van't Veer LJ: Molecular portraits and 70-gene prognosis signature are preserved throughout the metastatic process of breast cancer. Cancer Res 2005, 65:9|55-9158.

74. Perreard L, Fan C, Quackenbush JF, Mullins M, Gauthier NP, Nelson E, Mone M, Hansen H, Buys SS, Rasmussen K, Orrico AR, Dreher D, Walters R, Parker J, Hu Z, He X, Palazzo JP, Olopade OI, Szabo A, Perou CM, Bernard PS: Classification and risk stratification of invasive breast carcinomas using a real-time quantitative RT-PCR assay. Breast Cancer Res 2006, 8:R23.

75. UNC Microarray Database [https://genome.unc.edu/cgi-bin/ SMD/publication/viewPublication.pl?pub no $=62$ ]

76. Eisen MB, Spellman PT, Brown PO, Botstein D: Cluster analysis and display of genome-wide expression patterns. Proc Natl Acad Sci U S A 1998, 95: | 14863-|4868.

77. Eisen MB, Brown PO: DNA arrays for analysis of gene expression. Methods Enzymol 1999, 303:179-205.

78. Tusher V, Tibshirani R, Chu G: Significance analysis of microarrays applied to the ionizing radiation response. Proc Natl Acad Sci U SA 200I, 98:5II6-5I2I.

79. Hosack DA, Dennis G Jr., Sherman BT, Lane HC, Lempicki RA: Identifying biological themes within lists of genes with EASE. Genome Biol 2003, 4:R70.

80. KEGG: Kyoto Encyclopedia of Genes and Genomes [http:// www.genome.ad.jp/kegg/]

81. Ogata H, Goto S, Sato K, Fujibuchi W, Bono H, Kanehisa M: KEGG: Kyoto Encyclopedia of Genes and Genomes. Nucleic Acids Res 1999, 27:29-34.

82. BioCarta [http://www.biocarta.com]

83. Fan $C$, Oh DS, Wessels $L$, Weigelt $B$, Nuyten $D S$, Nobel $A B$, van't Veer LJ, Perou CM: Concordance among gene-expressionbased predictors for breast cancer. N Engl J Med 2006, 355:560-569.

Publish with Bio Med Central and every scientist can read your work free of charge

"BioMed Central will be the most significant development for disseminating the results of biomedical research in our lifetime. "

Sir Paul Nurse, Cancer Research UK

Your research papers will be:

- available free of charge to the entire biomedical community

- peer reviewed and published immediately upon acceptance

- cited in PubMed and archived on PubMed Central

- yours - you keep the copyright
BioMedcentral 